Atmos. Chem. Phys., 18, 12531-12550, 2018

https://doi.org/10.5194/acp-18-12531-2018

(C) Author(s) 2018. This work is distributed under

the Creative Commons Attribution 4.0 License.

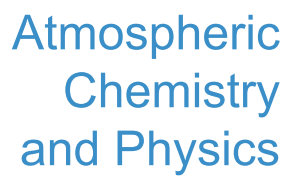

(c) (P)

\title{
Aerosol as a potential factor to control the increasing torrential rain events in urban areas over the last decades
}

\author{
Seoung Soo Lee ${ }^{1}$, Byung-Gon Kim ${ }^{2}$, Zhanqing Li ${ }^{1}$, Yong-Sang Choi ${ }^{3}$, Chang-Hoon Jung ${ }^{4}$, Junshik Um $^{5}$, \\ Jungbin Mok ${ }^{1}$, and Kyong-Hwan Seo $^{5}$ \\ ${ }^{1}$ Earth System Science Interdisciplinary Center, University of Maryland, Maryland \\ ${ }^{2}$ Department of Atmospheric Environmental Sciences, Gangneung-Wonju National University, \\ Gangneung, Gang-Won do, South Korea \\ ${ }^{3}$ Department of Environmental Science and Engineering, Ewha Womans University, Seoul, South Korea \\ ${ }^{4}$ Department of Health Management, Kyungin Women's University, Incheon, South Korea \\ ${ }^{5}$ Department of Atmospheric Sciences, Division of Earth Environmental System, \\ Pusan National University, Busan, South Korea
}

Correspondence: Seoung Soo Lee (cumulss@gmail.com, slee1247@umd.edu)

Received: 3 February 2018 - Discussion started: 20 February 2018

Revised: 30 July 2018 - Accepted: 15 August 2018 - Published: 29 August 2018

\begin{abstract}
This study examines the role played by aerosol in torrential rain that occurred in the Seoul area, which is a conurbation area where urbanization has been rapid in the last few decades, using cloud-system-resolving model (CSRM) simulations. The model results show that the spatial variability in aerosol concentrations causes the inhomogeneity of the spatial distribution of evaporative cooling and the intensity of associated outflow around the surface. This inhomogeneity generates a strong convergence field in which torrential rain forms. With the increases in the variability in aerosol concentrations, the occurrence of torrential rain increases. This study finds that the effects of the increases in the variability play a much more important role in the increases in torrential rain than the much-studied effects of the increases in aerosol loading. Results in this study demonstrate that for a better understanding of extreme weather events such as torrential rain in urban areas, not only changing aerosol loading but also changing aerosol spatial distribution since industrialization should be considered in aerosolprecipitation interactions.
\end{abstract}

\section{Introduction}

It has been reported that there has been an increase in the frequency of torrential rain in urban areas over the last decades (Bouvette et al., 1982; Diem and Brown, 2003; Fujibe, 2003; Takahashi, 2003; Burian and Shepherd, 2005; Shepherd, 2005; Chen et al., 2015). Over the last decades, population in urban areas has increased significantly. In $1950,30 \%$ of the whole population in the world lived in urban areas; however, in $2010,54 \%$ of the whole population lived in urban areas. It is predicted that in $2050,66 \%$ of the whole population will live in urban areas (United Nations, 2015). In addition, urban areas are the centers of economic activity and play a key role in economic productivity (United Nations, 2015). Hence, the increase in the frequency of torrential rain, which has substantial negative impacts on human life and properties by causing events such as flooding and landslide, particularly in urban areas has important social and economic implications.

Torrential rain in urban areas frequently involves highly inhomogeneous spatial distributions of precipitation (Dhar and Nandergi, 1993; Mannan et al., 2013). While some places in a metropolitan area experience light precipitation, others in the area experience extremely heavy precipitation or torrential rain for an identical mesoscale convective system (MCS) that covers the whole area (e.g., Sauer et al., 1984; Korea Meteorological Administration, 2011). Note that this 
type of MCS is forced by synoptic-scale temperature and humidity forcings. These synoptic-scale forcings tend to be spatially homogeneous in the MCS, which is on a mesoscale and thus much smaller than that of the forcings. Hence, these forcings tend to intensify all cloud cells in the MCS in an approximately homogeneous fashion, which tends to produce cloud cells with a similar intensity. These cloud cells with similar intensity are likely to result in a homogeneous distribution of precipitation over a domain of interest since cloud cells with similar intensity are likely to produce similar precipitation. This indicates that the consideration of the synoptic-scale forcings alone is not able to explain the occurrence of torrential rain, which is associated with inhomogeneous spatial distributions of precipitation. Note that numerous numerical weather prediction studies have utilized the concept of the synoptic-scale forcings to identify mechanisms that control the inhomogeneity of precipitation distributions and associated torrential rain. This is one of the reasons these studies have shown low forecast accuracy for torrential rain and not been able to provide a clear picture of the mechanisms (Mladek et al., 2000; Yeh and Chen, 2004; Mannan et al., 2013). The highly inhomogeneous distribution of precipitation means that there are highly inhomogeneous variables, processes, and forcings which disrupt the synopticforcing-induced homogeneity of MCSs in urban areas. Some of those forcings are mesoscale forcings that show mesoscale variability and, for example, are related to phenomena such as sea breeze fronts and lake breezes. In particular, in urban areas, due to strong heat fluxes at the surface, there is the urban heat island (UHI) effect, as another example of these phenomena. Examples of these variables and processes are cold pool, rear inflow, wind shear, and mesoscale vorticity. Aerosol is also one of the variables that has large spatial variability. In particular, urban aerosol particles are produced by randomly distributed sources (e.g., traffic), which enables aerosol to have large variability in urban areas.

It is well known that increasing aerosol loading alters cloud microphysical properties such as cloud particle size and autoconversion. Cloud liquid particles, which are droplets, collide and collect to grow into raindrops and this growth process is referred to as autoconversion. Collision and collection are more efficient when particle sizes are larger. Hence, increasing aerosol loading, which is known to reduce the particle size, reduces the efficiency of the growth of cloud liquid particles to raindrops via autoconversion. This results in more cloud liquid, which is not converted to raindrops, and thus in more cloud liquid mass as a source of evaporation and freezing. It has been shown that aerosol-induced increases in cloud liquid mass and associated increases in freezing of cloud liquid can enhance parcel buoyancy and thus invigorate convection (Khain et al., 2005; Rosenfeld et al., 2008; Li et al., 2011; Wang et al., 2014). Invigorated convection can enhance precipitation. Studies (e.g., van den Heever et al., 2006; Fan et al., 2009; Lebo and Seinfeld, 2011; Lebo, 2017) have shown that aerosol-induced invig- oration of convection and enhancement of precipitation depend on competition between aerosol-induced increases in buoyancy and those in hydrometeor loading, aerosol-induced increases in condensational heating, and associated invigoration in the warm sector of a cloud system. Other studies (e.g., Khain et al., 2008; Lee et al., 2008b; Fan et al., 2009) have shown that the invigoration-related enhancement of precipitation also depends on environmental conditions that are represented by wind shear, relative humidity, and instability.

Aerosol-induced increases in cloud liquid mass and associated increases in evaporation can intensify gust fronts, which in turn intensify subsequently developing convective clouds and enhance precipitation (Khain et al., 2005; Seifert and Beheng, 2006; Tao et al., 2007, 2012; van den Heever and Cotton, 2007; Storer et al., 2010; Lee and Feingold, 2013; Lee et al., 2017). Aerosol-induced invigoration and intensification of convection and associated convective clouds raise a hypothesis that the large spatial variability in aerosol in tandem with increasing aerosol loading can generate and enhance torrential rain, which can involve the inhomogeneity of precipitation and associated cloud intensity in urban areas. For example, cloud cells (in an MCS) sitting on a significant portion of a metropolitan area with a higher aerosol concentration can be invigorated more than those cells on the rest of the area with a lower aerosol concentration. This can lead to enhanced precipitation and possibly torrential rain at the portion with the higher aerosol concentration, while in the rest there can be less precipitation. This creates an inhomogeneity of precipitation distributions that can accompany torrential rain in the specific portion of the area. A further increase in aerosol concentration in the portion with the higher aerosol concentration will further enhance precipitation and torrential rain there and thus create a greater inhomogeneity of precipitation distributions. Motivated by the hypothesis and associated argument here, among the forcings, processes, and variables which have spatial variability, this study focuses on aerosol. To examine aerosol effects on clouds and precipitation, numerical simulations are performed by using a cloud-system-resolving model (CSRM) that resolves cloudscale microphysical and dynamic processes and simulates the effect of the variability and loading of aerosol on precipitation.

Using the CSRM, an observed MCS that involves deep convective clouds and torrential rain is simulated. Here, deep convective clouds reach the tropopause. For the simulations, we select an MCS over the Seoul area (in South Korea) that has a population of $\sim 25$ million and thus is one of the representative conurbation areas around the world. These simulations are to identify key mechanisms that are associated with cloud-scale microphysics and dynamics and explain the generation of the inhomogeneity of precipitation and associated torrential rain in terms of the spatial variability and loading of aerosol. 


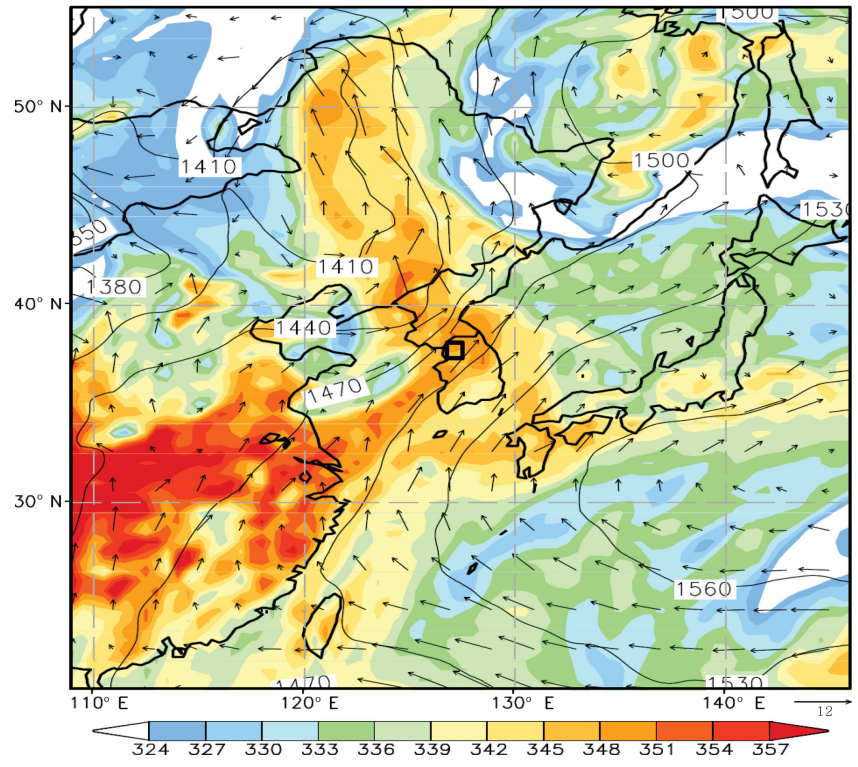

Figure 1. The $850 \mathrm{hPa}$ wind ( $\mathrm{m} \mathrm{s}^{-1}$, arrows), geopotential height ( $\mathrm{m}$, contours), and equivalent potential temperature ( $\mathrm{K}$, shaded) at 21:00 LST on 26 July 2011 over northeastern Asia. The rectangle on the Korean Peninsula marks Domain 3, which is explained in Sect. 3.2 and shown in Fig. 2.

\section{Case description}

The MCS was observed in the Seoul area, South Korea, over a period between 09:00 LST (local solar time) 27 July and 09:00 LST 28 July 2011. A significant amount of precipitation is recorded during this period, with a local maximum value of $\sim 200.0 \mathrm{~mm} \mathrm{~h}^{-1}$. This heavy rainfall caused flash floods and landslides, leading to the deaths of 60 people (Korea Meteorological Administration, 2011). At 21:00 LST 26 July 2011, favorable synoptic-scale features for the development of the selected MCS and heavy rainfall were observed. The western Pacific subtropical high (WPSH) was located over the southeast of South Korea and Japan, and there was a low-pressure trough over north China (Fig. 1). Low-level jets between the flank of the WPSH and the lowpressure system brought warm, moist air from the Yellow Sea to the Korean Peninsula (Fig. 1). Transport of warm and moist air by the southwesterly low-level jet is an important condition for the development of heavy rainfall events over the Korean Peninsula (Hwang and Lee, 1993; Lee et al., 1998; Seo et al., 2013).

\section{CSRM and simulations}

\subsection{CSRM}

As a CSRM, we use the Advanced Research Weather Research and Forecasting (ARW) model (version 3.3.1), which

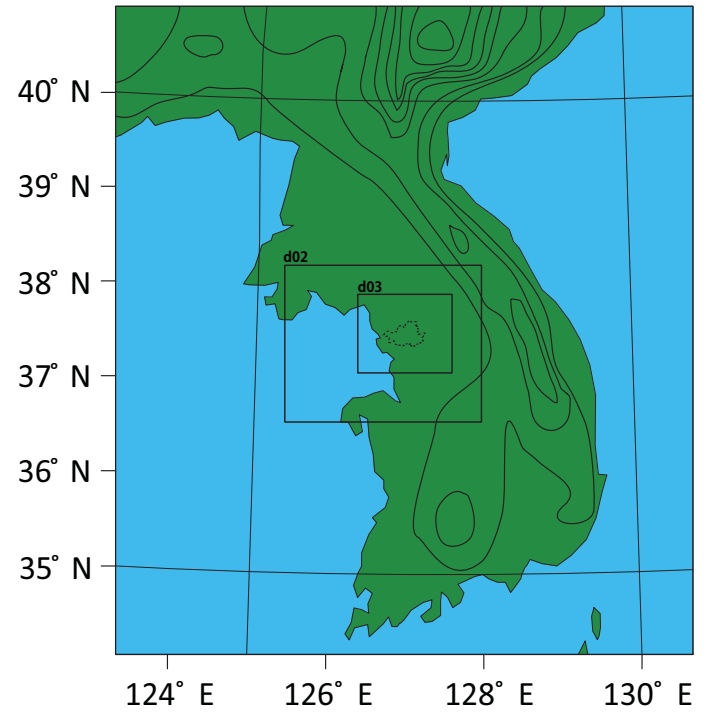

Figure 2. Triple-nested domains used in the CSRM simulations. The boundary of the figure itself is that of Domain 1, while the rectangles marked by "d02" and "d03" represent the boundary of Domain 2 and Domain 3, respectively. The dotted line represents the boundary of Seoul and terrain heights are contoured every $250 \mathrm{~m}$.

is a nonhydrostatic compressible model. Prognostic microphysical variables are transported with a fifth-order monotonic advection scheme (Wang et al., 2009). Shortwave and longwave radiation parameterizations have been included in all simulations by adopting the Rapid Radiation Transfer Model (RRTM; Mlawer et al., 1997; Fouquart and Bonnel, 1980). The effective sizes of hydrometeors are calculated in a microphysics scheme that is adopted by this study and the calculated sizes are transferred to the RRTM. Then, the effects of the effective sizes of hydrometeors on radiation are calculated in the RRTM.

To represent microphysical processes, the CSRM employs a bin scheme. The bin scheme employed is based on the Hebrew University Cloud Model (HUCM) described by Khain et al. (2011). The bin scheme solves a system of kinetic equations for size distribution functions for water drops, ice crystals (plate, columnar, and branch types), snow aggregates, graupel, hail, and cloud condensation nuclei (CCN). Each size distribution is represented by 33 mass doubling bins, i.e., the mass of a particle $m_{k}$ in the $k$ bin is determined as $m_{k}=2 m_{k-1}$.

\subsection{Control run}

For a three-dimensional simulation of the observed MCS, i.e., the control run, two-way interactive triple-nested domains with a Lambert conformal map projection as shown in Fig. 2 are adopted. A domain with a $500 \mathrm{~m}$ resolution covering the Seoul area (Domain 3) is nested in a domain with a $1.5 \mathrm{~km}$ resolution (Domain 2), which in turn is nested in 
a domain with a $4.5 \mathrm{~km}$ resolution (Domain 1). The length of Domain 3 in the east-west direction is $220 \mathrm{~km}$, while the length in the north-south direction is $180 \mathrm{~km}$. The lengths of Domain 2 and Domain 3 in the east-west direction are 390 and $990 \mathrm{~km}$, respectively, and those in the north-south direction are 350 and $1100 \mathrm{~km}$, respectively. The Seoul area is a conurbation area that is centered in Seoul and includes Seoul and surrounding highly populated cities. Hence, the Seoul area is composed of multiple cities whose total population is $\sim 25$ million. The boundary of Seoul, which has the largest population among those cities, is marked by a dotted line in Fig. 2. Black contours in Fig. 2 represent terrain heights. They indicate that most high terrain is located on the eastern part of the Korean Peninsula and the Seoul area is not affected by high terrain. All domains have 84 vertical layers with a terrain following the sigma coordinate, and the model top is $50 \mathrm{hPa}$. Note that a cumulus parameterization scheme is used in Domain 1 but not used in Domain 2 and Domain 3 where convective rainfall generation is assumed to be explicitly resolved. Here, we use a cumulus parameterization scheme that was developed by Kain and Fritsch $(1990,1993)$. This scheme is shown to work reasonably well for resolutions that are similar to what is used for Domain 1 (Gilliland and Rowe, 2007).

Reanalysis data, which are produced by the Met Office Unified Model (Brown et al., 2012) and recorded continuously every $6 \mathrm{~h}$ on a $0.11^{\circ} \times 0.11^{\circ}$ grid, provide the initial and boundary conditions of potential temperature, specific humidity, and wind for the simulation. These data represent the synoptic-scale environment. For the control run, we employ an open lateral boundary condition. Using the Noah land surface model (LSM; Chen and Dudhia, 2001), surface heat fluxes are predicted.

The current version of the ARW model assumes horizontally homogeneous aerosol properties. For the control run that focuses on the effect of aerosol on torrential rain in an urban area (i.e., Seoul area) where aerosol properties such as composition and number concentration vary significantly in terms of time and space, we abandon this assumption of homogeneity and consider the spatiotemporal variability in aerosol properties over the urban area. For this, we develop an aerosol preprocessor that is able to represent the variability in aerosol properties. This aerosol preprocessor interpolates observed background aerosol properties such as aerosol mass (e.g., $\mathrm{PM}_{10}$ ) at observation sites to model grid points and time steps. This aerosol preprocessor is now implemented in the ARW model.

The variability in aerosol properties is observed by surface sites that measure $\mathrm{PM}_{10}$ in the Seoul area. These sites are distributed with about $1 \mathrm{~km}$ distance between them and measure aerosol mass every $\sim 10 \mathrm{~min}$, which enables us to resolve the variability with high spatiotemporal resolutions. However, the measurement of other aerosol properties such as aerosol composition and size distributions at those sites is absent. There are additional sites of the AErosol RObotic

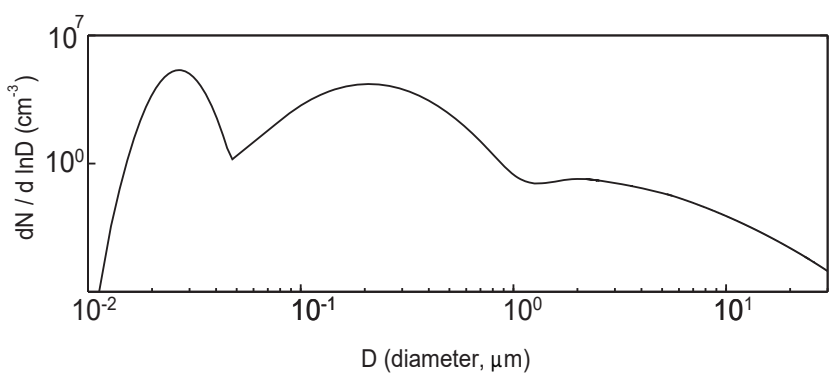

Figure 3. Aerosol size distribution at the surface. $N$ represents aerosol number concentration per unit volume of air and $D$ represents aerosol diameter.

NETwork (AERONET; Holben et al., 2001) in the Seoul area. Distances between these AERONET sites are $\sim 10 \mathrm{~km}$; hence, they do not provide data whose resolutions are as high as those of the $\mathrm{PM}_{10}$ data. However, the AERONET sites provide information on aerosol composition and size distributions. While using data from the high-resolution $\mathrm{PM}_{10}$ sites to represent the variability in aerosol properties over the Seoul area, we use the relatively low-resolution data from the AERONET sites to represent aerosol composition and size distributions.

AERONET measurements indicate that overall, aerosol particles in the Seoul area during the MCS period follow a trimodal lognormal distribution and aerosol particles, on average, are an internal mixture of $60 \%$ ammonium sulfate and $40 \%$ organic compound. This organic compound is assumed to be water soluble and composed of (by mass) $18 \%$ levoglucosan $\left(\mathrm{C}_{6} \mathrm{H}_{10} \mathrm{O}_{5}\right.$, density $=1600 \mathrm{~kg} \mathrm{~m}^{-3}$, van 't Hoff factor $=1), 41 \%$ succinic acid $\left(\mathrm{C}_{6} \mathrm{O}_{4} \mathrm{H}_{6}\right.$, density $=1572 \mathrm{~kg} \mathrm{~m}^{-3}$, van 't Hoff factor $=3)$, and $41 \%$ fulvic acid $\left(\mathrm{C}_{33} \mathrm{H}_{32} \mathrm{O}_{19}\right.$, density $=1500 \mathrm{~kg} \mathrm{~m}^{-3}$, van 't Hoff factor $=5$ ) based on a simplification of observed chemical composition. This mixture is adopted to represent aerosol chemical composition in this study. In this study, aerosol-radiation interactions, which are the effect of aerosol on radiation via the reflection, scattering, and absorption of shortwave and longwave radiation by aerosol before its activation, are not considered. This is partially motivated by the fact that the mixture includes chemical components that absorb solar radiation insignificantly compared to strong radiation absorbers such as black carbon. Based on the AERONET observation, in this study, the trimodal lognormal distribution is assumed for the size distribution of background aerosol as exemplified in Fig. 3. Stated differently, it is assumed that the size distribution of background aerosol at all grid points and time steps has size distribution parameters or the shape of distribution that is identical to that in Fig. 3. The assumed shape of the size distribution of background aerosol is obtained by averaging size distribution parameters (i.e., modal radius and standard deviation of nuclei, accumulation, and coarse modes each, and the partition of aerosol number among those modes) over the 
AERONET sites and the MCS period. With these assumption and adoption, $\mathrm{PM}_{10}$ is converted to background aerosol number concentrations. Figure $4 \mathrm{a}$ and $\mathrm{b}$ show example spatial distributions of background aerosol number concentrations at the surface in Domain 3 (which covers the Seoul area), which are applied to the control run and represented by black contours. These distributions in Fig. $4 \mathrm{a}$ and $\mathrm{b}$ are calculated based on the surface observation in Domain 3. Blue contours in Fig. 4a and b surround areas with observed heavy precipitation on which this study focuses. In this study, when a precipitation rate at the surface is $60 \mathrm{~mm} \mathrm{~h}^{-1}$ or above, precipitation is considered heavy precipitation. There is no one universal designated rate (of precipitation) above which precipitation is considered heavy precipitation and the designated rate varies among countries. As a precipitation rate, $60 \mathrm{~mm} \mathrm{~h}^{-1}$ is around the upper end of the variation. Those blue contours are further discussed in Sect. 4. Purple lines in Fig. 4a and b mark the eastern part of where there is substantial transition from high-value aerosol concentrations to low-value aerosol concentrations. In this transition part, there is reduction in aerosol concentrations by more than a factor of 10 from $\sim 9000$ to $\sim 700 \mathrm{~cm}^{-3}$.

In clouds, aerosol size distributions evolve with sinks and sources, which include advection and droplet nucleation (Fan et al., 2009). Aerosol activation is calculated according to the Köhler theory, i.e., aerosol particles with radii exceeding a critical value at a grid point are activated to become droplets based on predicted supersaturation, and the corresponding bins of the aerosol spectra are emptied. After activation, aerosol mass is transported within hydrometeors by collision-coalescence and removed from the atmosphere once hydrometeors that contain aerosols reach the surface. It is assumed that in the planetary boundary layer (PBL), background aerosol concentrations do not vary with height but above the PBL background aerosol concentrations reduce exponentially with height. It is also assumed that in non-cloudy areas, aerosol size and spatial distributions are set to follow background counterparts. In other words, once clouds disappear completely at any grid point, aerosol size distributions and number concentrations at those points recover to background counterparts. This assumption has been used by numerous CSRM studies and proven to simulate overall aerosol properties and their impacts on clouds and precipitation reasonably well (Morrison and Grabowski, 2011; Lebo and Morrison, 2014; Lee et al., 2016). This assumption indicates that we do not consider the effects of clouds and associated convective and turbulent mixing on the properties of background aerosol. Also, the prescription of those properties (e.g., number concentration, size distribution, and chemical composition) explained above indicates that this study does not take aerosol physical and chemical processes into account. This enables the confident isolation of the sole effects of given background aerosol on clouds and precipitation in the Seoul area, which has not been understood well,
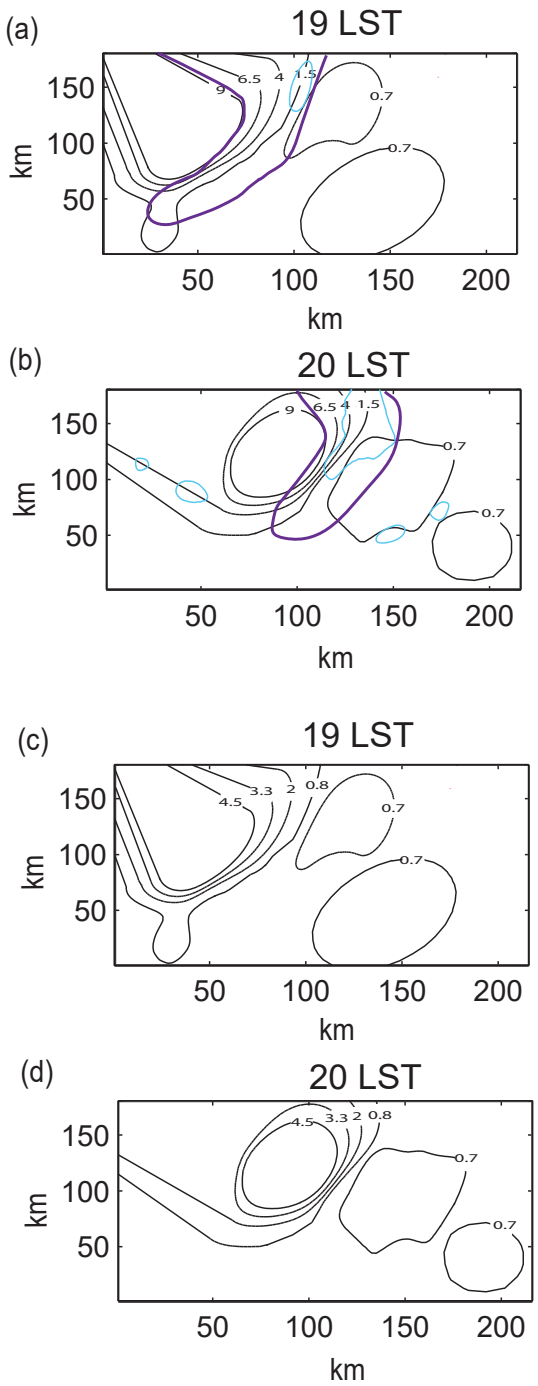

Figure 4. Spatial distributions of background aerosol number concentrations at the surface (black contours; in $\times 10^{3} \mathrm{~cm}^{-3}$ ) and the boundary of each area that has a precipitation rate of $60 \mathrm{~mm} \mathrm{~h}^{-1}$ or above (blue contours) in Domain 3 at (a) 19:00 and (b) 20:00 LST. Purple lines in panels (a) and (b) mark a part of the domain in which there is a substantial reduction in aerosol number concentrations (see text for the details of purple lines). Panels (c) and (d) are the same as panels (a) and (b), respectively, but with reduced contrast in aerosol number concentrations for the low-aerosol run (see text for the details of reduced contrast).

by excluding those aerosol processes and cloud effects on background aerosol.

\subsection{Additional runs}

As seen in Fig. 4a and $b$ at 19:00 and 20:00 LST 27 July 2011, there is a large variability in background aerosol concentrations in the Seoul area. This variability is generated by contrast between the high aerosol concentrations in the western part of the domain where aerosol concen- 
Table 1. Summary of simulations.

\begin{tabular}{|c|c|c|}
\hline Simulations & $\begin{array}{l}\text { Contrast in aerosol } \\
\text { number } \\
\text { concentration }\end{array}$ & $\begin{array}{l}\text { The effect of } \\
\text { cloud liquid } \\
\text { evaporation on } \\
\text { temperature }\end{array}$ \\
\hline Control run & Observed & Present \\
\hline Low-aerosol run & $\begin{array}{l}\text { Reduced by a } \\
\text { factor of } 2\end{array}$ & Present \\
\hline Control-noevp run & Observed & Absent \\
\hline Low-aerosol-noevp run & $\begin{array}{l}\text { Reduced by a } \\
\text { factor of } 2\end{array}$ & Absent \\
\hline Control-homoge run & Absent & Present \\
\hline $\begin{array}{l}\text { Low-aerosol- } \\
\text { homoge run }\end{array}$ & Absent & Present \\
\hline
\end{tabular}

tration is greater than $1500 \mathrm{~cm}^{-3}$, and the low aerosol concentrations in the eastern part of the domain where aerosol concentration is $\sim 700 \mathrm{~cm}^{-3}$ or less. As mentioned above, this study focuses on the effect of the spatial variability and loading (or concentrations) of aerosol on precipitation. To better identify and elucidate the effect, the control run is repeated but with the abovementioned contrast that is reduced. To reduce contrast, over the whole simulation period, the concentrations of background aerosol in the western part of the domain are reduced by a factor of 2 , while those in the eastern part do not change. This means that the reduction in the variability accompanies that in aerosol concentrations, which enables us to examine both the effects of the variability and those of concentrations. Note that high and low aerosol concentrations on the left (or western) side and the right (or eastern) side of the domain, respectively, are maintained throughout the whole simulation period, although the location of the boundary between those sides changes with time. Here, in the process of the reduction in contrast, no changes are made for aerosol chemical compositions and size distributions in both parts of the domain. As examples, the spatial distribution of background aerosol concentrations at the surface with reduced contrast at 19:00 and 20:00 LST 27 July 2011 is shown in Fig. 4c and d, respectively. With reduced contrast and concentrations, the variability and concentrations of aerosol are lower in this repeated run than in the control run. The repeated simulation has low variability and concentrations of aerosol as compared to the control run and thus is referred to as the "low-aerosol" run. Comparisons between the control run and the low-aerosol run give us a chance to better understand roles played by the spatial variability and loading of aerosol in the spatial distribution of precipitation, which involves torrential rain.

In addition to the control run and the low-aerosol run, there are more simulations that are performed to better understand the effect of aerosol on precipitation here. To isolate the effects of aerosol concentrations on precipitation from those of aerosol spatial variability or vice versa, the control run and the low-aerosol run are repeated with homogeneous spatial distributions of aerosol. These homogeneous spatial distributions mean that there is no contrast in aerosol number concentrations between the western part of the domain and the eastern part, and aerosol number concentrations do not vary over the domain. The repeated simulations are referred to as the "control-homoge" run and the "low-aerosol-homoge" run. The analyses of model results below indicate that differences in precipitation between the control run and the low-aerosol run are closely linked to cloud liquid evaporative cooling and to elucidate this linkage, the control run and the low-aerosol run are repeated again by turning off cooling from cloud liquid evaporation. These repeated simulations are referred to as the "control-noevp" run and the "lowaerosol-noevp" run. While a detailed description of those repeated simulations is given in Sect. 4.3, a brief description is given in Table 1.

\section{Results}

In this study, analyses of results are performed only in the Seoul area (or Domain 3) where the $500 \mathrm{~m}$ resolution is applied. Hence, in the following, the description of the simulation results and their analyses is only over Domain 3, unless otherwise stated.

\subsection{Meteorological fields, microphysics, and precipitation}

\subsubsection{Meteorological fields and cumulative precipitation}

Figure 5 shows the observed and simulated vertical profiles of potential temperature, water vapor mass density, $u$ wind speed, and $v$-wind speed, which represent meteorological fields. Radiosonde data as observation data are averaged over observation sites in the domain and the simulation period, while simulated meteorological fields are averaged over the domain and the simulation period to obtain the profiles. Positive (negative) $u$-wind speed represents eastward (westward) wind speed, while positive (negative) $v$-wind speed represents northward (southward) wind speed. Comparisons between the observed profiles and the simulated counterparts show that overall differences between them are within $\sim 10 \%$ of observed values. Hence, with confidence, it can be considered that the simulation of meteorological fields is performed reasonably well.

The area-mean precipitation rate at the surface smoothed over $3 \mathrm{~h}$ for the control run and the low-aerosol run is depicted by solid lines in Fig. 6. Dotted lines in Fig. 6 depict the precipitation rate for the repeated control run and low-aerosol run and will be discussed in Sect. 4.3. The simulated precipitation rate in the control run follows the observed counterpart well, which demonstrates that simulations perform reasonably well. Here, observed precipitation is obtained from 


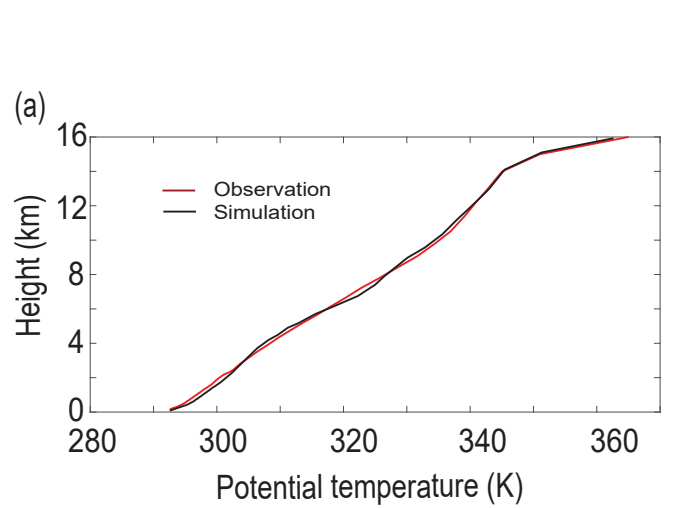

(b)

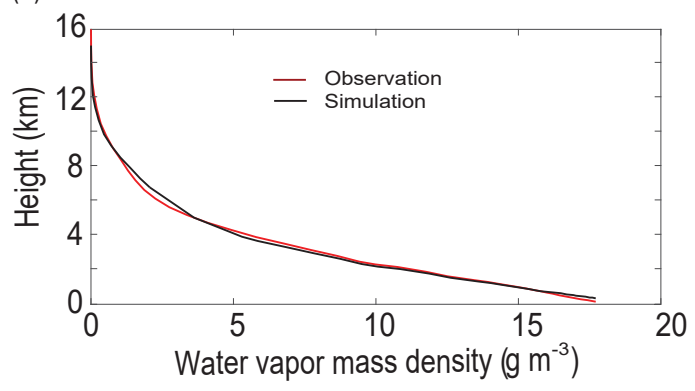

(c)

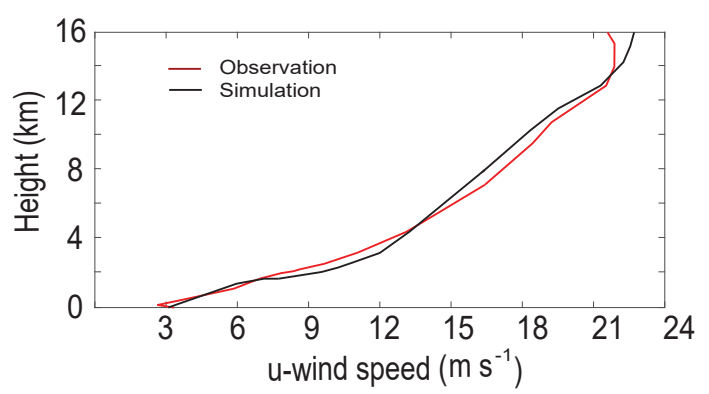

(d)

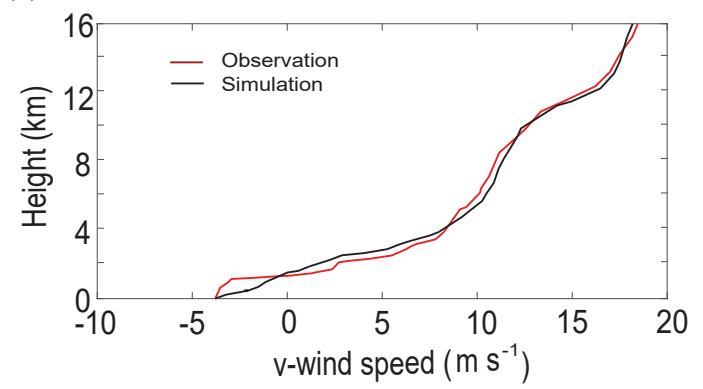

Figure 5. Vertical distributions of the averaged (a) potential temperature, (b) water vapor mass density, (c) $u$-wind speed, and (d) $v$ wind speed. Positive (negative) $u$-wind speed represents eastward (westward) wind speed, while positive (negative) $v$-wind speed represents northward (southward) wind speed. Observations are averaged over observation sites in Domain 3 and the simulation period, while simulations are averaged over Domain 3 and the simulation period. (a)

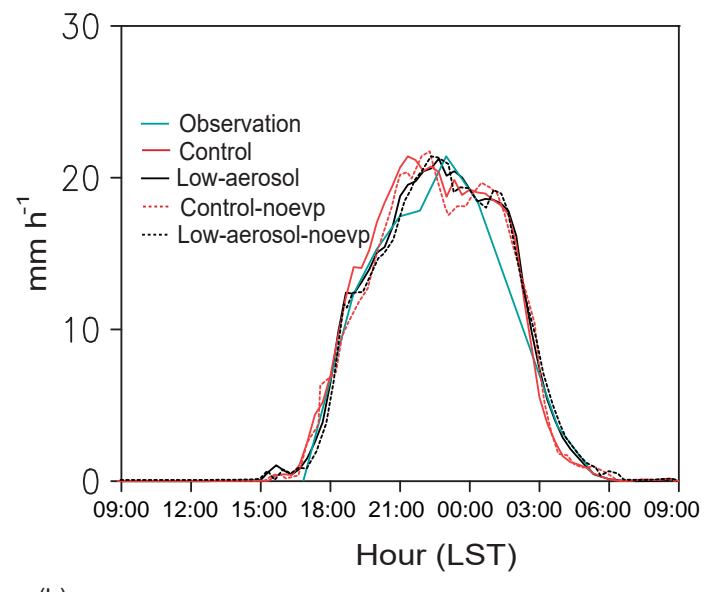

(b)

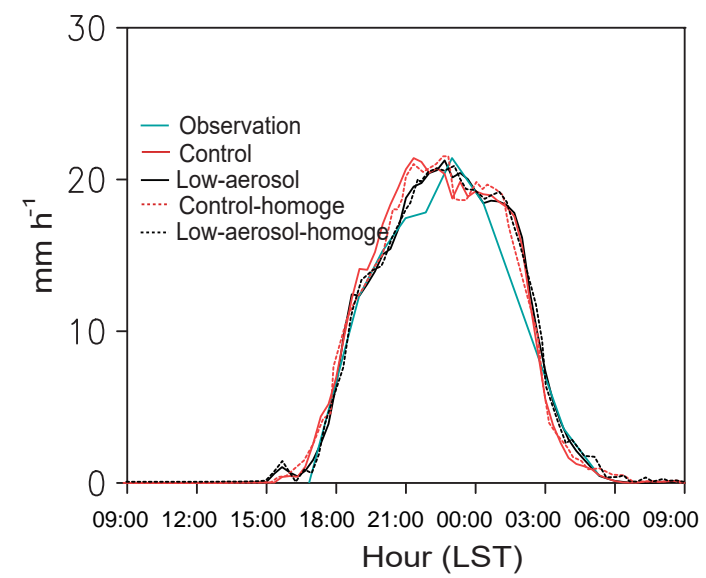

Figure 6. Time series of the area-mean precipitation rates at the surface smoothed over $3 \mathrm{~h}$ for the control run, the low-aerosol run, and observations in Domain 3. In panel (a), the rates in the controlnoevp run and the low-aerosol-noevp are additionally shown, while in panel (b), the rates in the control-homoge run and the lowaerosol-homoge are additionally shown.

measurement by rain gauges that are parts of the automatic weather station (AWS) at the surface. The AWS has a spatial resolution of $\sim 3 \mathrm{~km}$. Also, the temporal evolution of the mean precipitation rate in the control run is very similar to that in the low-aerosol run. Associated with this similarity, the averaged cumulative precipitation over the domain at the last time step for the control run is $154.7 \mathrm{~mm}$, which is just $\sim 3 \%$ greater than $150.2 \mathrm{~mm}$ for the low-aerosol run.

\subsubsection{Precipitation fields and frequency distributions}

Figure $7 \mathrm{a}, \mathrm{b}$, and $\mathrm{c}$ show frequency distributions of precipitation rates that are collected over all time steps and all grid points at the surface in the simulations. In Fig. 7, solid lines represent frequency distributions for the control run and the low-aerosol run, while dashed lines represent those for the 

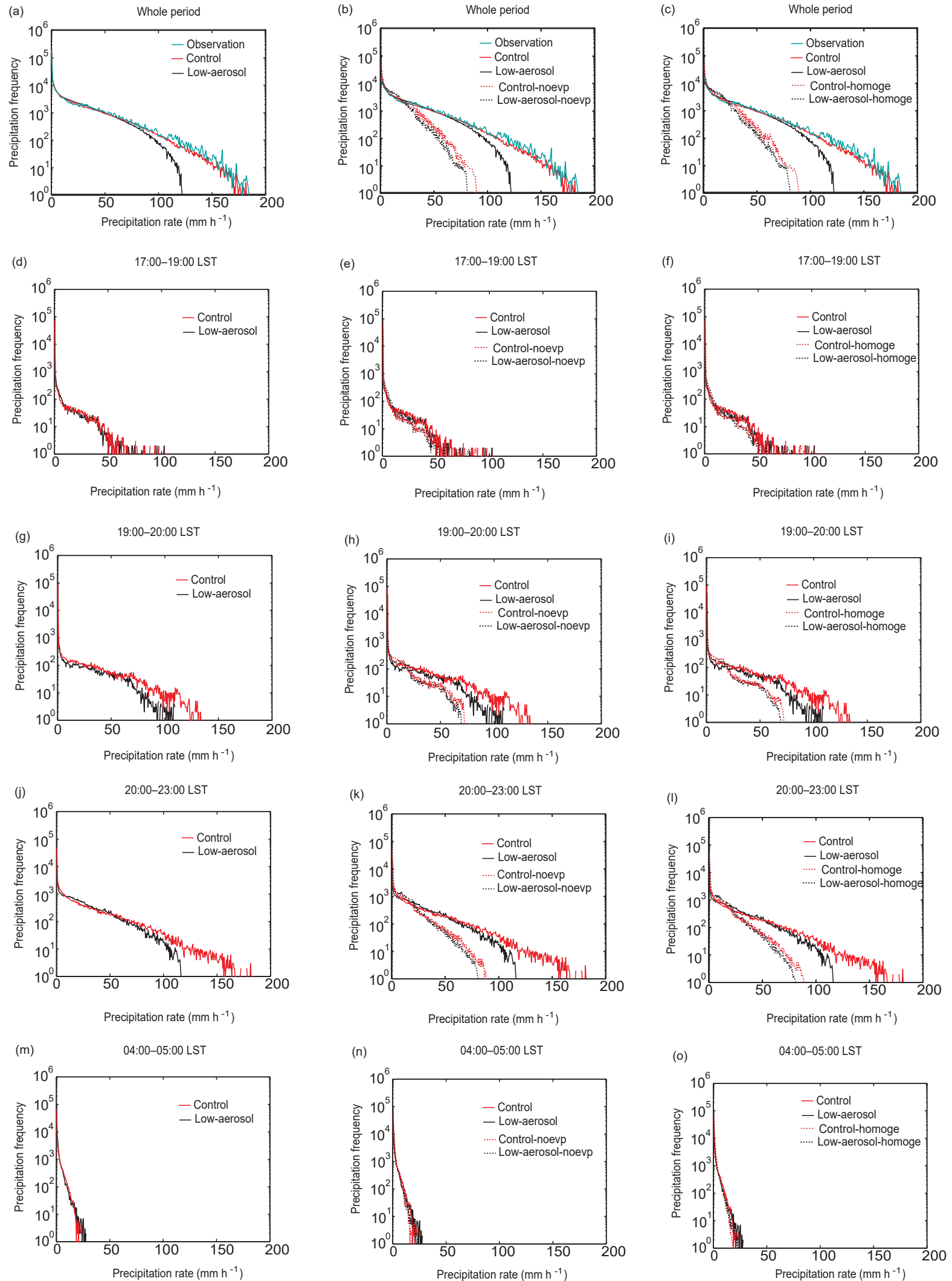

Figure 7. Frequency distributions of the precipitation rates at the surface, which are collected over the whole domain, for (a, b, c) the whole simulation period, $(\mathbf{d}, \mathbf{e}, \mathbf{f})$ a period between 17:00 and 19:00 LST, $(\mathbf{g}, \mathbf{h}, \mathbf{i})$ a period between 19:00 and 20:00 LST, (j, k, l) a period between 20:00 and 23:00 LST, and (m, n, o) a period between 04:00 and 05:00 LST. In panels (a), (b), and (c) observed frequency, which is interpolated to the simulation time steps and grid points, is also shown. 
repeated control run and low-aerosol run, which will be described in Sect. 4.3. Figure 7a, d, g, j, and m show frequency distributions only for the control run and the low-aerosol run. The other panels in Fig. 7 are supposed to show distributions only for the repeated control run and low aerosol run; however, for comparisons among the control run, the lowaerosol run, and the repeated runs, the control run and the low-aerosol run are displayed as well in those panels.

In Fig. 7a, b, and c, frequency distributions of observed precipitation rates that are interpolated to grid points and time steps in the simulations are also shown. The observed maximum precipitation rate is $\sim 180 \mathrm{~mm} \mathrm{~h}^{-1}$, which is similar to that in the control run. Also, observed frequency distribution is consistent with the simulated counterpart in the control run, although it appears that particularly for heavy precipitation with rates above $60 \mathrm{~mm} \mathrm{~h}^{-1}$, the simulated frequency is underestimated compared to the observed counterpart. The overall difference in frequency distributions between observation and the control run is much smaller than those between the control run and the low-aerosol run. Hence, we assume that the difference between observation and the control run is considered negligible compared to that among the runs. Based on this, when it comes to a discussion about the difference between the control run and the lowaerosol run, results in the control run can be assumed to be benchmark results against which the effect of decreases in the spatial variability and concentrations of aerosol on results in the low-aerosol run can be assessed.

While we do not see a large difference in cumulative precipitation between the control run $(154.7 \mathrm{~mm})$ and the lowaerosol run $(150.2 \mathrm{~mm})$, the frequency distribution of precipitation rates shows distinctively different features between the control run and the low-aerosol run (Fig. 7a). For precipitation with rates above $60 \mathrm{~mm} \mathrm{~h}^{-1}$ or heavy precipitation, cumulative frequency is $\sim 60 \%$ higher for the control run. For certain ranges of precipitation rates above $60 \mathrm{~mm} \mathrm{~h}^{-1}$, there are increases in cumulative frequency by a factor of as much as $\sim 10$ to $\sim 100$. Moreover, for precipitation rates above $120 \mathrm{~mm} \mathrm{~h}^{-1}$, while there is the presence of precipitation in the control run, there is no precipitation in the low-aerosol run. Hence, we see that there are significant increases in the frequency of heavy precipitation in the control run compared to that in the low-aerosol run.

Figure 8 shows spatial distributions of precipitation rates at the surface. Purple lines in Fig. 8 mark the eastern part of where there is substantial transition from high-value aerosol concentrations to low-value aerosol concentrations as in Fig. 4. In this transition part, as explained in Fig. 4, there is reduction in aerosol concentrations by more than a factor of 10. Figure $8 \mathrm{a}$ and $\mathrm{b}$ show those distributions at 17:00 LST 27 July 2011 corresponding to initial stages of the precipitating system in the control run and the low-aerosol run, respectively. At 17:00 LST, there is a small area of precipitation around the northwest corner of the domain in both the control run and the low-aerosol run. This implies that a small cloud system develops around the northwest corner of the domain at 17:00 LST. The size of the system and its precipitation area grow with time and at 19:00 LST, the size is much larger (Fig. 8c and d). The maximum precipitation rate reaches $\sim 100 \mathrm{~mm} \mathrm{~h}^{-1}$ when time progresses to 19:00 LST (Fig. 7d). Heavy precipitation is concentrated in a specific area (surrounded by the green rectangle) in both of the runs (Fig. 8c and d). The green rectangle surrounds a specific area where more than $90 \%$ of the events of heavy precipitation (over the domain) with rates above $60 \mathrm{~mm} \mathrm{~h}^{-1}$ occur in each of the runs at 19:00 LST. Since heavy precipitation starts to form around 19:00 LST, the green rectangle starts to be identified around 19:00 LST. Contrast in precipitation between the green rectangle and the other areas in the domain generates an inhomogeneity in the spatial distribution of precipitation. The location of the specific area in the control run is consistent with the location of heavy precipitation in observation as seen in comparisons between Figs. 4a, 8c, and 9a. Figure 9a shows the blue contour, which surrounds areas with observed heavy precipitation in Fig. 4a, and the green rectangle, which surrounds the specific area where more than $90 \%$ of the events of heavy precipitation occur in Fig. 8c. In Fig. 9a, the purple line, which marks a substantial transition in aerosol concentrations in Fig. 4a, is also shown. The good consistency among the locations demonstrates that the simulation of the spatial distribution of heavy precipitation is performed reasonably well. Between 17:00 and 19:00 LST, we do not see significant differences in the frequency distribution of precipitation rates, particularly in heavy precipitation with rates above $60 \mathrm{~mm} \mathrm{~h}^{-1}$ between the control run and the low-aerosol run (Fig. 7d).

By 20:00 LST, the maximum rate of torrential rain reaches $\sim 130 \mathrm{~mm} \mathrm{~h}^{-1}$ for the control run and $\sim 110 \mathrm{~mm} \mathrm{~h}^{-1}$ for the low-aerosol run (Fig. $7 \mathrm{~g}$ ). Associated with this, between 19:00 and 20:00 LST, significant differences in frequency distributions, particularly for heavy precipitation between the control run and the low-aerosol run, start to appear (Fig. 7g). At 20:00 LST as seen in Fig. 8e and in the previous hours, in the control run more than $90 \%$ of heavy precipitation events are concentrated in a specific area that is surrounded by the green rectangle. Note that only in this specific area, does extremely heavy precipitation with rates above $100 \mathrm{~mm} \mathrm{~h}^{-1}$ occur. In the low-aerosol run, the extremely heavy precipitation with rates above $100 \mathrm{~mm} \mathrm{~h}^{-1}$ also occurs only in a particular area, which is surrounded by the green rectangle, at 20:00 LST (Fig. 8f). At 20:00 LST, as seen in Fig. 4b, observation shows that there are five spots of heavy precipitation. The location of the largest spot where most heavy precipitation events occur is similar to that of the specific area that is surrounded by the green rectangle in the control run as seen in comparisons between Figs. 4b, 8e, and 9b. Figure 9b shows the blue contour and the purple line from Fig. $4 \mathrm{~b}$ and the green rectangle from Fig. 8e. This again demonstrates that the simulation of the spatial distribution of heavy precipitation is performed with fairly good confidence. 
Control

(a)

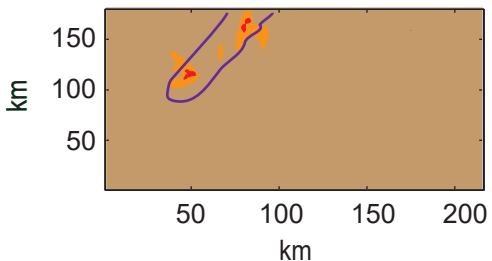

(c)

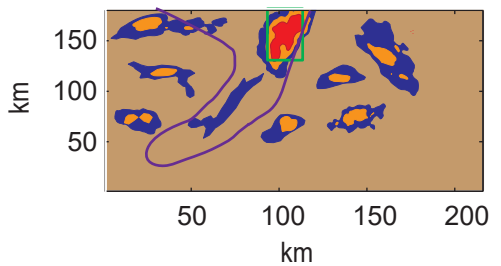

20:00 LST

(e)

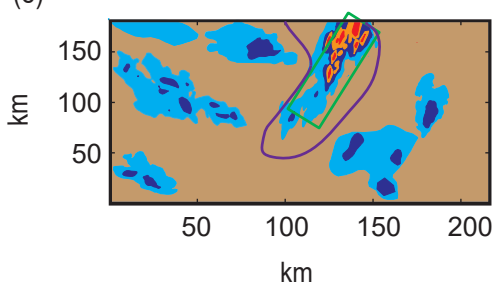

(g)

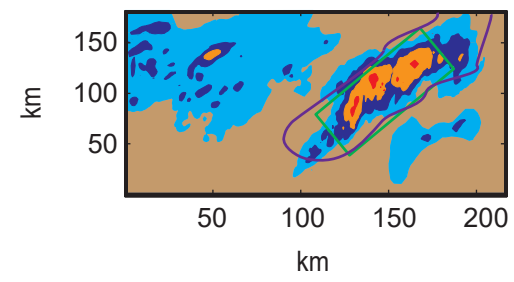

17:00 LST

(b)

19:00 LST

(d)

(f)

(h)
Low-aerosol
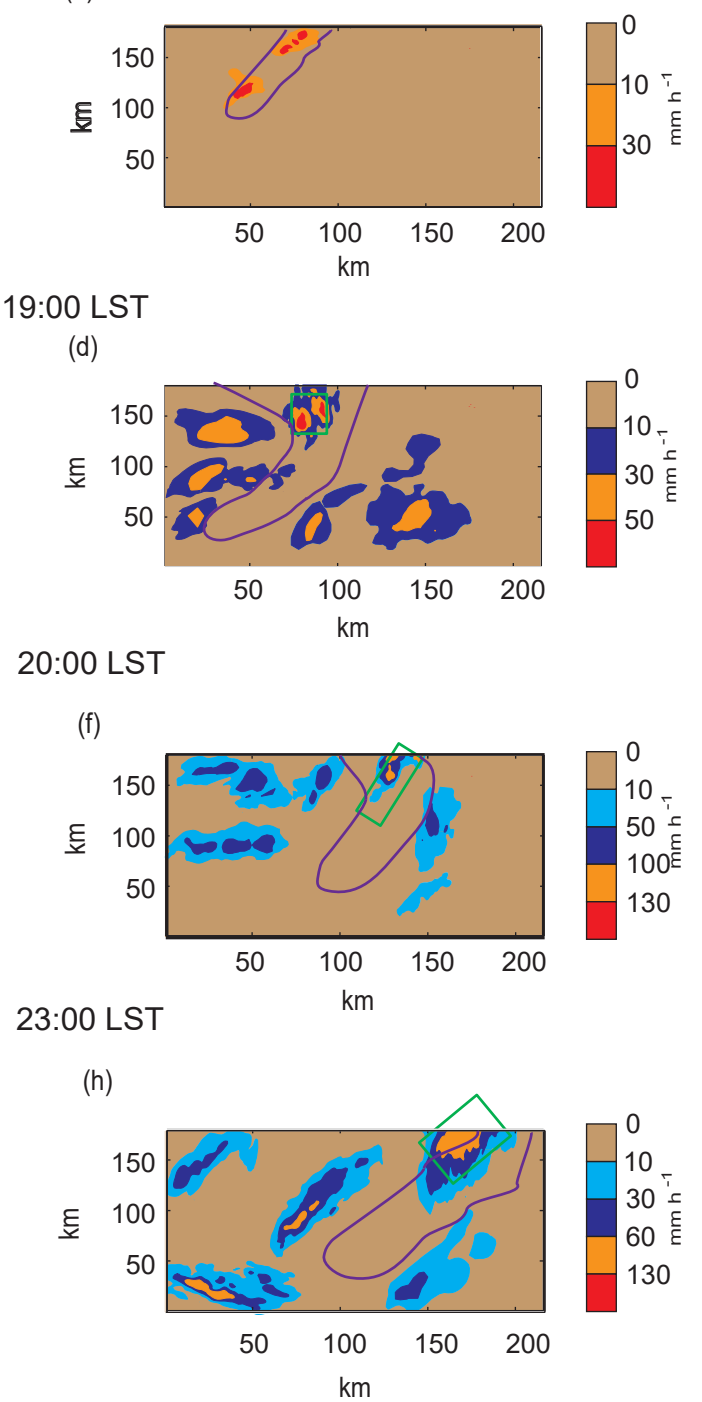

Figure 8. Spatial distributions of precipitation rates at the surface. Green rectangles mark areas with heavy precipitation and are described in detail in text. Purple lines mark the eastern part of where there is substantial transition from high-value aerosol concentrations to low-value aerosol concentrations as in Fig. 4. Panels (a), (c), (e), and (g) are for the control run, while panels (b), (d), (f), and (h) are for the low-aerosol run. Panels (a) and (b) are for 17:00 LST, and panels (c) and (d) are for 19:00 LST. Panels (e) and (f) are for 20:00 LST, and panels (g) and (h) are for 23:00 LST.

The system propagates eastwards after 20:00 LST in a way that its easternmost part is closer to the east boundary of the domain as seen in comparisons between Fig. 8e (Fig. 8f) and Fig. 8g (Fig. 8h) for the control (low-aerosol) run. As seen in Fig. $8 \mathrm{~g}$ and in the previous hours, for the control run more than $90 \%$ of heavy precipitation events are concentrated in a specific area (surrounded by the green rectangle) at 23:00 LST. However, in the low-aerosol run, heavy precipitation is not concentrated in a specific area at 23:00 LST. Unlike the green rectangle in the control run at 23:00 LST, the green rectangle at 23:00 LST in the low-aerosol run sur- rounds an area where $\sim 50 \%$ of heavy precipitation events are located, although the rectangle surrounds the largest area with heavy precipitation among heavy precipitation areas in the low-aerosol run. For a period between 20:00 and 23:00 LST compared to that between 19:00 and 20:00 LST, the maximum precipitation rate rises up to $\sim 180 \mathrm{~mm} \mathrm{~h}^{-1}$ in the control run; however, in the low-aerosol run, the maximum precipitation rate stays at $\sim 120 \mathrm{~mm} \mathrm{~h}^{-1}$ (Fig. $7 \mathrm{~g}$ and j). Hence, there is the presence of precipitation rates between $\sim 120$ and $\sim 180 \mathrm{~mm} \mathrm{~h}^{-1}$ in the control run, while there is their absence in the low-aerosol run for the period between 
(a)

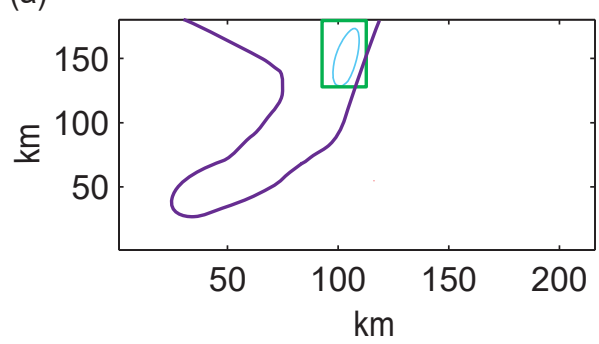

(b)

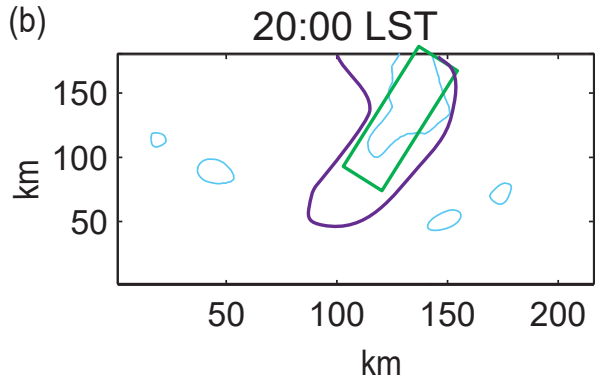

Figure 9. Boundary of each area which has the observed surface precipitation rate of $60 \mathrm{~mm} \mathrm{~h}^{-1}$ or above (blue contours) and a specific area (surrounded by the green rectangle in the control run and described in the text related to Fig. 8) where heavy precipitation is concentrated in the control run in Domain 3 at (a) 19:00 LST and (b) 20:00 LST. Purple lines are the same as in Fig. 8.

20:00 and 23:00 LST. This reflects that increases in the frequency of torrential rain, which are induced by increases in the spatial variability and loading of aerosol, enhance as the system evolves from its initial stage before 20:00 LST to its mature stage between 20:00 and 23:00 LST.

Of interest is that the green rectangle is included in an area which is surrounded by the purple line in all panels with different times in Fig. 8 and further discussion for this matter is provided in Sect. 4.2. After 23:00 LST 27 July 2011, the precipitating system enters its decaying stage. Figure $7 \mathrm{~m}$ shows precipitation-rate frequency in the control run and the low-aerosol run for a period between 04:00 and 05:00 LST 28 July 2011. As seen in Fig. 7m, with the progress of the decaying stage, the maximum precipitation rate reduces down to $\sim 25 \mathrm{~mm} \mathrm{~h}^{-1}$ as an indication that heavy precipitation disappears and the system is nearly at the end of its life cycle.

\subsection{Dynamics}

\section{Convergence}

For the examination of condensation which is the main source of precipitation, convergence fields at the surface, where updrafts that produce condensation originate, are obtained and the column-averaged condensation rates are superimposed on them. Other processes such as deposition and freezing produce the mass of solid hydrometeors and act as sources of precipitation; however, their contribution to precipitation is $\sim 1$ order of magnitude smaller than that by condensation in the control run and the low-aerosol run. Hence, here, among sources of precipitation, we focus on condensation. Convergence and condensation fields are again superimposed on shaded precipitation fields as shown in Fig. 10. In Fig. 10, convergence and condensation fields are represented by white and yellow contours, respectively. When it comes to the convergence field in the green rectangle in Fig. 10, which starts to be formed around 19:00 LST and is composed of convergence lines, the field in the rectangle in the control run is stronger than that in the low-aerosol run. The averaged intensity of the convergence field over an area with non-zero convergence in the green rectangle and over the simulation period is $0.013 \mathrm{~s}^{-1}$ in the control run, while the averaged intensity is $0.007 \mathrm{~s}^{-1}$ in the low-aerosol run. The convergence field in the green rectangle is strongest among convergence lines over the whole domain and, associated with this, stronger updrafts and greater condensation develop over that field in the green rectangle than in the other lines over the whole domain in each of the runs.

Figure 11 shows horizontal distributions of wind vector field (arrows) superimposed upon fields of convergence, condensation, and precipitation. In general, particularly from 19:00 LST on, in the area with high-value aerosol concentrations to the west of the strong convergence field (surrounded by the green rectangle), there are greater horizontal wind speeds than in the area with low-value aerosol concentrations to the east of the strong convergence field in the control run. As seen in comparisons between the location of the rectangle and that of the purple line, which mark the transition zone for aerosol concentrations, the area to the west of the rectangle has higher aerosol concentrations than that to the east. In the area with high-value aerosol concentrations, there is greater cloud liquid evaporation occurring than in the area with low-value aerosol concentrations in the control run as shown in Fig. 12a. Figure 12a shows the vertical distribution of the time- and domain-averaged cloud liquid and rain evaporation rates over each of the areas to the west and east of the strong convergence field, which is surrounded by the green rectangle, and over the period between 17:00 and 19:00 LST for the control run and the low-aerosol run. For the calculation of the averaged values in Fig. 12, the area to the west (east) of the strong convergence field is set to include all parts of the north-south direction, which is the $y$ direction, and the vertical domains but only a portion of the east-west direction domain, which is the $x$-direction domain that extends from the western boundary of Domain 3 to $90 \mathrm{~km}$ where the western boundary of the green rectangle at 19:00 LST is located (from $110 \mathrm{~km}$ where the eastern boundary of the green rectangle at 19:00 LST is located to the eastern boundary of Domain 3) in Domain 3 for the control run. For the low-aerosol run, the area to the west (east) of the strong convergence field is identical to that in the control run except for the fact that the area includes a portion of 
Control

(a)

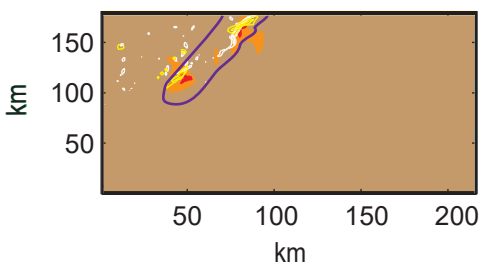

(c)

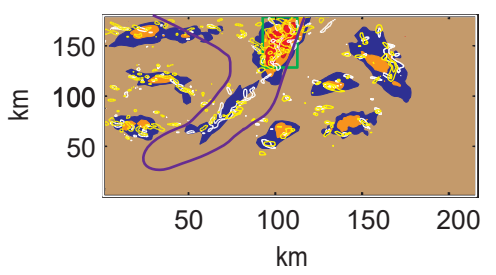

(e)

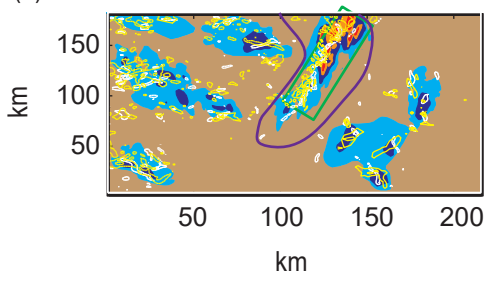

(g)

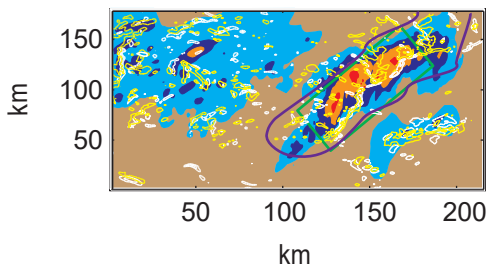

Low-aerosol

17:00 LST

(b)
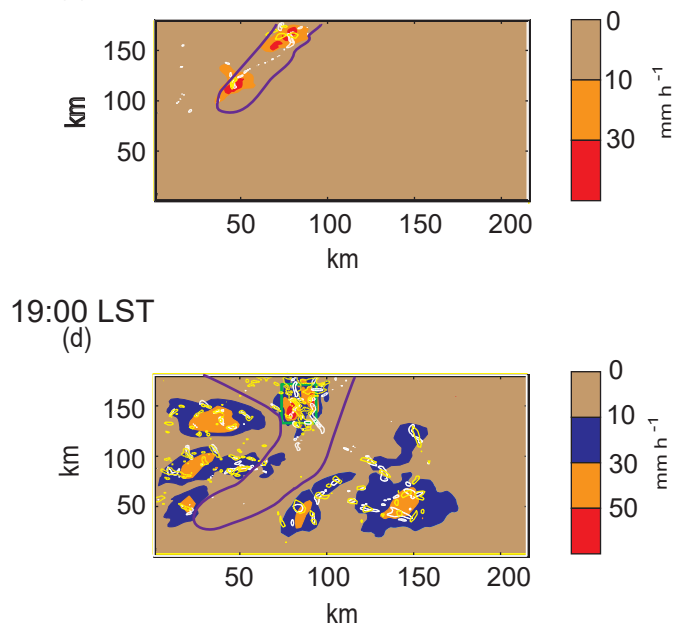

20:00 LST

(f)

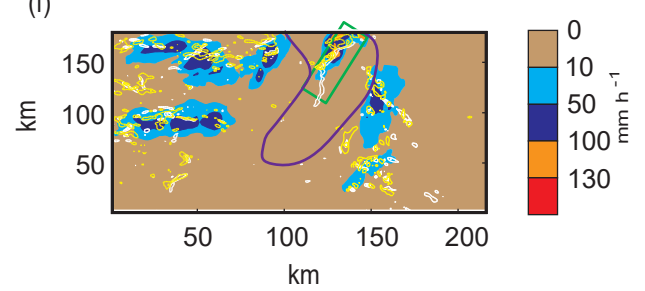

23:00 LST

(h)

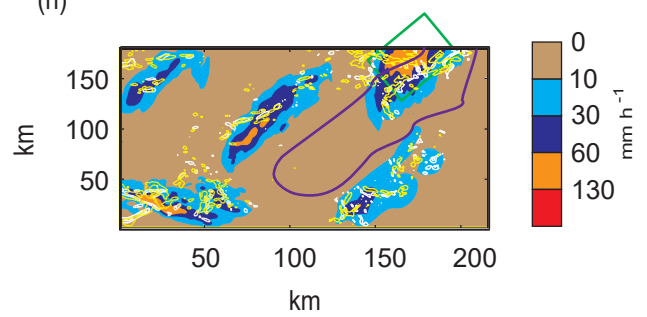

Figure 10. Same as Fig. 8 but with convergence at the surface (white contours) and the column-averaged condensation rates (yellow contours) which are superimposed on the precipitation field. In panels (a) and (b), white contours are at 0.4 and $0.7 \times 10^{-2} \mathrm{~s}^{-1}$ and yellow contours are at 0.4 and $0.9 \mathrm{~g} \mathrm{~m}^{-3} \mathrm{~h}^{-1}$. In panels (c) and (d), white contours are at 0.9 and $1.7 \times 10^{-2} \mathrm{~s}^{-1}$ and yellow contours are at 0.9 and $1.5 \mathrm{~g} \mathrm{~m}^{-3} \mathrm{~h}^{-1}$. In panels (e) and (f), white contours are at 1.4 and $2.3 \times 10^{-2} \mathrm{~s}^{-1}$ and yellow contours are at 1.3 and $2.9 \mathrm{~g} \mathrm{~m}^{-3} \mathrm{~h}^{-1}$. In panels (g) and (h), white contours are at 2.1 and $3.5 \times 10^{-2} \mathrm{~s}^{-1}$ and yellow contours are at 2.3 and $3.8 \mathrm{~g} \mathrm{~m}^{-3} \mathrm{~h}^{-1}$.

the $x$-direction domain that extends from the western boundary of Domain 3 to $70 \mathrm{~km}$ where the western boundary of the green rectangle at 19:00 LST is located (from $90 \mathrm{~km}$ where the eastern boundary of the green rectangle at 19:00 LST is located to the eastern boundary of Domain 3) in Domain 3.

High-value aerosol concentrations reduce autoconversion and in turn increase cloud liquid as a source of evaporation and thus increase cloud liquid evaporation compared to lowvalue aerosol concentrations. In addition, high-value aerosol concentrations produce high-value cloud droplet number concentration and the associated high-value surface areas of droplets. The surface of droplets is where condensation occurs and as shown by Lee et al. (2009) and a recent study by Fan et al. (2018), the high-value surface areas cause highervalue condensation compared to the situation with low-value aerosol concentrations that lead to lower-value condensation. The averaged condensation rate over the abovementioned area to the west (east) of the strong convergence field and over the period between 17:00 and 19:00 LST is 1.28 (0.97) $\mathrm{g} \mathrm{m}^{-3} \mathrm{~h}^{-1}$ in the control run. This further increases cloud liquid (as a source of evaporation) and thus its evaporation in the area with high-value aerosol concentrations. Also, 
Control Low-aerosol

17:00 LST

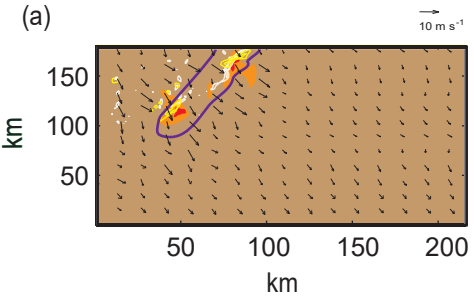

(b)

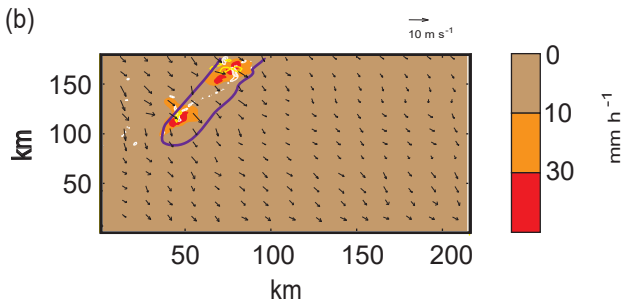

(c)

19:00 LST

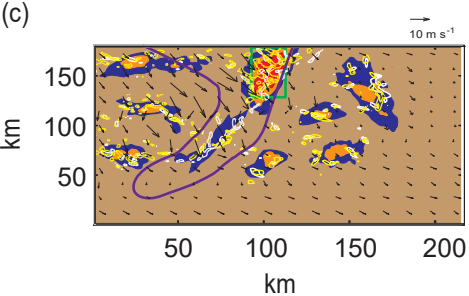

(d)

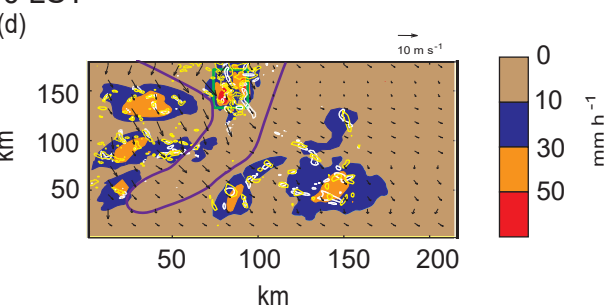

20:00 LST

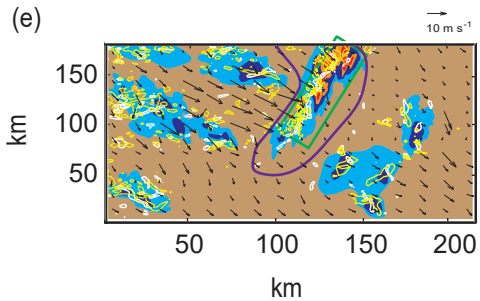

(f)

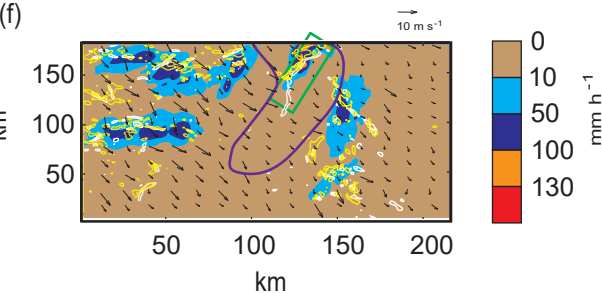

23:00 LST

(g)

(h)
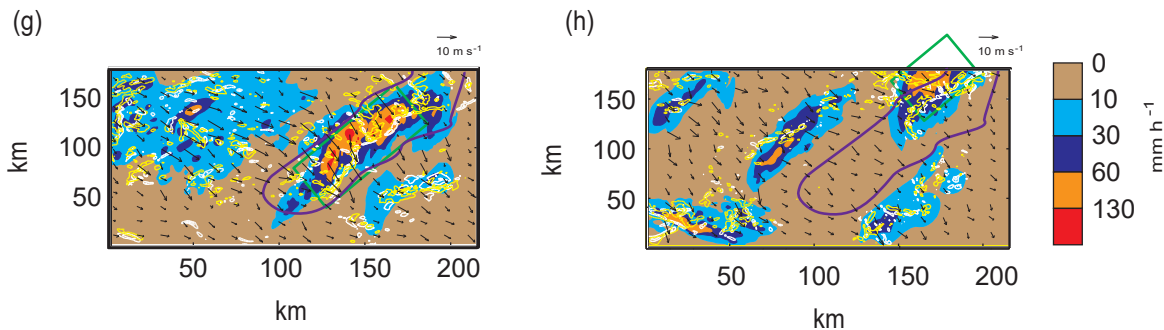

Figure 11. Same as in Fig. 10 but with wind vector fields (arrows), which are superimposed on the precipitation, convergence, and condensation fields.

with high-value aerosol concentrations, there is an increase in the surface-to-volume ratio of cloud droplets and this increases evaporation efficiency and thus cloud liquid evaporation compared to the situation with low-value aerosol concentrations. However, mainly due to an increase in the size of raindrops and their associated decrease in the surface-tovolume ratio, which is induced by high-value aerosol concentrations, rain evaporation reduces compared to the situation with low-value aerosol concentrations as also shown in van den Heever et al. (2011). Increases in cloud liquid evaporation in turn enhance negative buoyancy, which induces stronger downdrafts in the area with high-value aerosol concentrations than in the area with low-value aerosol concentrations in the control run particularly between 17:00 and 19:00 LST as seen in Fig. 12b. Sublimation and melting also enhance negative buoyancy; however, their contribution is $\sim 1$ order of magnitude smaller than the contribution by cloud liquid evaporation. Hence, here, we focus on cloud liquid evaporation. Figure $12 \mathrm{~b}$ shows the vertical distribution of the time- and domain-averaged downdraft mass fluxes over each of the areas to the west and east of the strong convergence field (surrounded by the green rectangle) for the control run and the low-aerosol run over the period between 17:00 and 19:00 LST. Previous studies have shown that aerosol-induced increases in cloud liquid evaporation are closely linked to the enhancement of the intensity of downdrafts (Lee et al., 2008a, b, 2013; Lee, 2017). Cloud liquid or droplets in downdrafts move together with downdrafts; thus, 


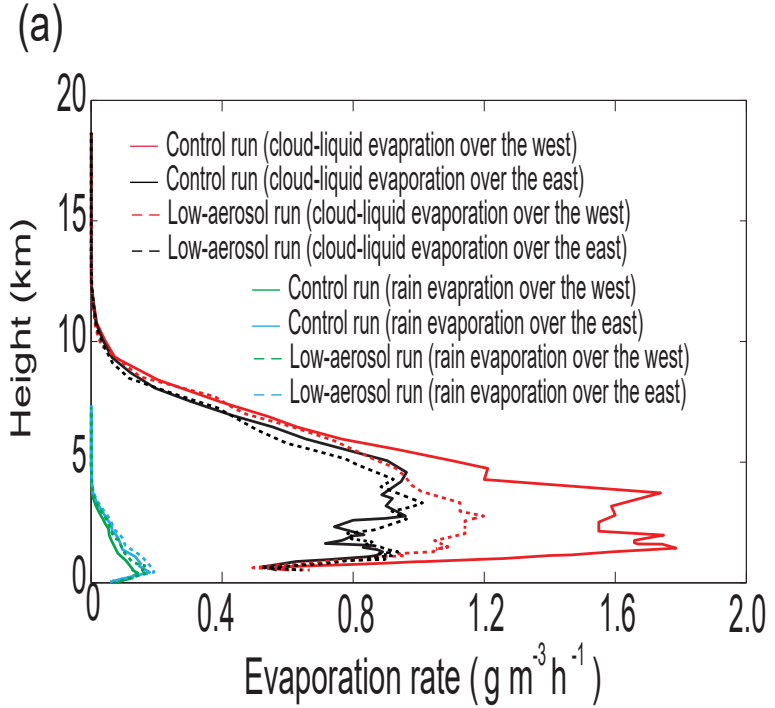

(b)

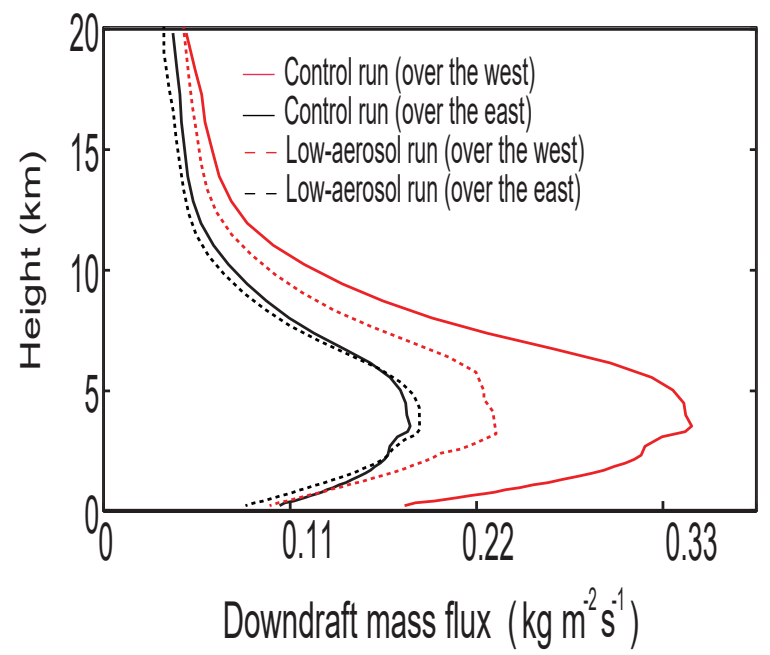

Figure 12. Vertical distributions of the time- and domainaveraged (a) cloud liquid and rain evaporation rates and (b) downdraft mass fluxes over each of the areas to the west and east of the strong convergence field for the control run and the low-aerosol run over a period between 17:00 and 19:00 LST (see text for details).

when downdrafts descend, cloud liquid descends while being included in downdrafts. Cloud liquid in the descending downdrafts evaporates. More evaporation of cloud liquid provides greater negative buoyancy to downdrafts so that they accelerate more (Byers and Braham, 1949; Grenci and Nese, 2001).

After reaching the near-surface altitudes below $\sim 3 \mathrm{~km}$, in the control run, stronger downdrafts spread out as stronger outflow or horizontal movement, as seen in the area with high-value aerosol concentrations, compared to those in the area with low-value aerosol concentrations around
19:00 LST in Fig. 11c. The outflow in the area with highvalue aerosol concentrations accelerates, due to evaporation on its path, as it moves southeastwards from the northern and western boundaries of the domain. The outflow accelerates until it collides with surrounding air that has weaker horizontal movement in the area with low-value aerosol concentrations. This collision mainly occurs in the places where the transition between high-value aerosol concentrations and low-value aerosol concentrations is located (surrounded by the purple line) as seen in Fig. 11c. This collision creates the strong convergence field around 19:00 LST, which is surrounded by the green rectangle in those places in the control run as seen in Fig. 11c. Hence, most of the strong convergence field (surrounded by the green rectangle) is included in the transition zone between high-value and low-value aerosol concentrations (which is surrounded by the purple line) in the control run (Fig. 11c). The strong convergence field in the green rectangle generates a large amount of condensation and cloud liquid and this large amount of cloud liquid produces not only heavy precipitation but also high-degree of evaporation. Then, high-degree of evaporation in turn contributes to the occurrence of a stronger convergence field in the green rectangle, which establishes feedbacks between the convergence field, condensation, heavy precipitation, and evaporation. This enables the intensification of downdrafts and horizontal wind to the west of the convergence field shown in the green rectangle, the convergence field, and the increases in heavy precipitation with time, while the convergence field shown in the green rectangle is advected eastwards in the control run as seen in Figs. 7g, $\mathrm{j}$ and 11e and g. As seen in Fig. 11e and g, even after 19:00 LST, the convergence field shown in the green rectangle stays within the transition zone between the high-value and low-value aerosol concentrations (which is surrounded by the purple line) during its eastward advection. This indicates that the collision explained above between strong outflow and surrounding weak wind, which is essential for the formation of the convergence field shown in the green rectangle, continuously occurs in the transition zone even after 19:00 LST.

Note that, associated with aerosol concentrations in the western part of the domain, which are 2 times greater in the control run than in the low-aerosol run, there are differences in aerosol concentrations 2 times greater between the area with high-value aerosol concentrations and that with lowvalue aerosol concentrations in the control run than in the low-aerosol run. This leads to a transition in aerosol concentrations 2 times greater, particularly in the transition zone surrounded by the purple line in the control run than in the low-aerosol run (Fig. 4). Associated with this, there is a greater reduction in autoconversion and increases in cloud liquid and surface-to-volume ratio of cloud droplets in the area with high-value aerosol concentrations in the control run than in the low-aerosol run. Then, there is greater evaporation, intensity of downdrafts, and associated outflow and its acceleration during its southeastward movement around the 
surface in that area in the control run than in the low-aerosol run (Figs. 11 and 12). This means that there is stronger collision between outflow and the surrounding air in the control run than in the low-aerosol run, and stronger collision forms the strong convergence field (in the green rectangle), which is much more intense in the control run than in the low-aerosol run as seen in Figs. 10 and 11. Over this much more intense convergence field, there is the formation of stronger updrafts that are able to form stronger convection, which is in turn able to produce more events of heavy precipitation in the control run than in the low-aerosol run (Fig. 7). The more intense strong convergence field in the green rectangle establishes stronger feedbacks between the convergence field, condensation, heavy precipitation, and evaporation in the control run than in the low-aerosol run. Hence, differences in intensity of the convergence field shown in the green rectangle and in the heavy precipitation between the runs become greater as time progresses (Figs. 7, 10, and 11).

\subsection{Sensitivity tests}

\subsubsection{Evaporative cooling}

It is discussed that cloud liquid evaporative cooling plays an important role in the formation of the strong convergence field where most of heavy precipitation occurs (surrounded by the green rectangle) in the control run. To confirm this role, we repeat the control run and the low-aerosol run with cooling from cloud liquid evaporation turned off and cooling from rain evaporation left on. The repeated control run and the low-aerosol run are referred to as the control-noevp run and the low-aerosol-noevp run, respectively. In these repeated runs, cloud liquid mass reduces due to cloud liquid evaporation, although cloud liquid evaporation does not affect temperature.

The temporal evolution of precipitation rates in the control-noevp run and the low-aerosol-noevp run is similar to that in the control run and the low-aerosol run (Fig. 6a). However, due to the absence of cloud liquid evaporative cooling, there is no formation of strong outflow and convergence field (as seen in wind field and the green rectangle in the control run and the low-aerosol run) in these repeated runs as shown in Fig. 13a and b. Figure 13a and b show wind vector and convergence fields at the surface over the whole domain in the control-noevp run and the low-aerosol-noevp run, respectively, at 23:00 LST, which corresponds to the mature stage of the system. Note that the strong convergence field is clearly distinguishable in its intensity and length from any other convergence lines in each of the control run and the low-aerosol run as seen in Figs. 10 and 11. However, there is no field in each of the repeated runs that is distinguishable in its intensity and length from other lines as seen in Fig. 13a and b. This leads to the situation in which there is no particular convergence field in the control-noevp run that produces many more events of heavy precipitation than in the low-aerosol-noevp run. As seen in Fig. 7h and k, associated with this, differences in the frequency of heavy precipitation with rates above $60 \mathrm{~mm} \mathrm{~h}^{-1}$ between the repeated runs are much smaller than those between the control run and the lowaerosol run, particularly for the period between 19:00 and 23:00 LST, although the control-noevp run shows a greater frequency of heavy precipitation than the low-aerosol-noevp run. This results in much smaller differences in heavy precipitation between the repeated runs than between the control run and the low-aerosol run for the whole simulation period as seen in Fig. 7b. This demonstrates that cloud liquid evaporative cooling and its differences between the control run and the low-aerosol run play a key role in many more events of heavy precipitation in the control run than in the low-aerosol run.

\subsubsection{Variability in aerosol concentrations}

Note that between the control run and the low-aerosol run, there are changes not only in the spatial variability in aerosol concentrations but also in aerosol concentrations. This means that differences between those runs are caused not only by changes in the variability but also by changes in aerosol concentrations. Although there have been many studies on the effects of changes in aerosol concentrations on heavy precipitation, studies on those effects of changes in the variability have been rare. Motivated by this, as a preliminary step to the understanding of those effects of changes in the variability, here, we attempt to isolate the effects of changes in the variability on heavy precipitation from those in aerosol concentrations or vice versa. For this purpose, the control run and the low-aerosol run are repeated with homogeneous spatial distributions of background aerosol concentrations. These repeated runs are referred to as the control-homoge run and the low-aerosol-homoge run. In the control-homoge run (low-aerosol-homoge run), aerosol concentrations over the domain are fixed at one value, which is the domainaveraged concentration of the background aerosol in the control run (the low-aerosol run), at each time step. Hence, in the control-homoge run and the low-aerosol-homoge run, the variability (or contrast) in the spatial distribution of aerosol concentrations between the area with high-value aerosol concentrations and that with low-value aerosol concentrations is removed, which achieves homogeneous spatial distributions.

The temporal evolution of precipitation rates in the control-homoge run and the low-aerosol-homoge run is similar to that in the control run and the low-aerosol run (Fig. 6b). However, with the homogeneity in the spatial distribution of aerosol concentrations, there is no formation of strong outflow and thus strong convergence field that is distinguishable from any other convergence lines in the control-homoge run and low-aerosol-homoge run as seen in Fig. 13c and d. Figure $13 \mathrm{c}$ and $\mathrm{d}$ show wind vector and convergence fields over the whole domain at 23:00 LST in the control-homoge run and the low-aerosol-homoge run, respectively. In the absence 


\section{3:00 LST}
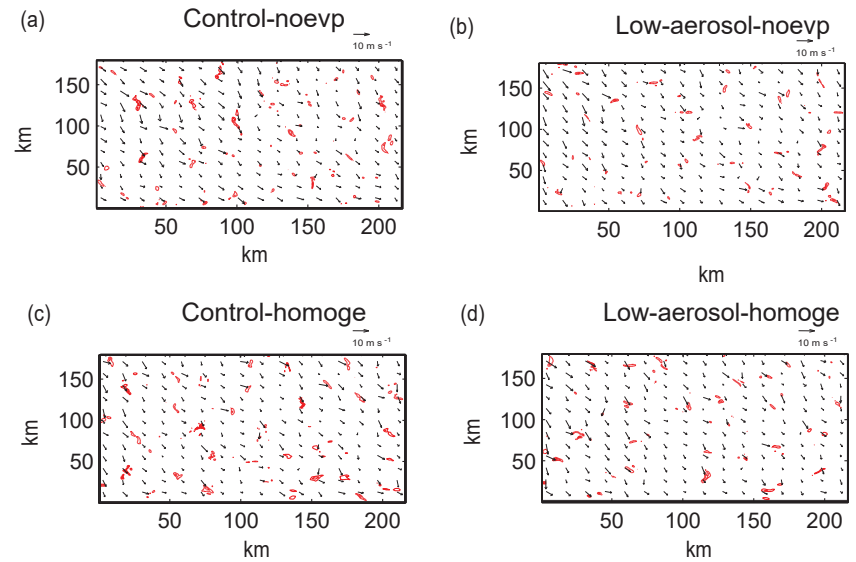

Figure 13. Spatial distributions of convergence (red contours) and wind vector (arrows) at the surface at 23:00 LST. Panels (a), (b), (c), and (d) are for the control-noevp run, the low-aerosol-noevp run, the control-homoge run, and the low-aerosol-homoge run, respectively, and contours are at 2.1 and $3.5 \times 10^{-2} \mathrm{~s}^{-1}$.

of the variability between the area with high-value aerosol concentrations and that with low-value aerosol concentrations, there are no differences in evaporative cooling between those areas and thus there is no strong outflow or convergence field which is distinguishable from any other lines.

Comparisons between the control run and the controlhomoge run (the low-aerosol run and the low-aerosolhomoge run) isolate the effects of the variability on heavy precipitation from those of aerosol concentrations whose averaged value is set at an identical value at each time step in the runs. Due to the absence of the variability in the spatial distribution of aerosol concentrations and the associated strong convergence field, the frequency of heavy precipitation in the control-homoge run and in the low-aerosolhomoge run is, on average, just $\sim 18 \%$ and $\sim 13 \%$ of that in the control run and in the low-aerosol run, respectively, for the whole simulation period (Fig. 7c). Hence, the presence of the variability alone (in the absence of changes in aerosol concentrations) increases the number of the heavy precipitation events by a factor of $\sim 5$ or $\sim 10$. This presence alone also results in a substantial increase in the maximum precipitation rate in the control run and the low-aerosol run compared to the repeated runs. Between the low-aerosol run and the low-aerosol-homoge run, the increase is from $80 \mathrm{~mm} \mathrm{~h}^{-1}$ in the low-aerosol-homoge run to $120 \mathrm{~mm} \mathrm{~h}^{-1}$ in the low-aerosol run, while between the control run and the control-homoge run, the increase is significant and from $90 \mathrm{~mm} \mathrm{~h}^{-1}$ in the control-homoge run to $180 \mathrm{~mm} \mathrm{~h}^{-1}$ in the control run (Fig. 7c). Here, we see that even without the effects of changes in aerosol concentrations, the presence of the variability alone is able to cause significant enhancement of heavy precipitation in terms of its frequency and maximum value.

Remember that there is an identical domain-averaged background aerosol concentration at each time step between the control run and the control-homoge run and between the low-aerosol run and the low-aerosol-homoge run. Hence, changes in the averaged aerosol concentration between the control-homoge run and the low-aerosol-homoge run are identical to those between the control run and the low-aerosol run. With these identical changes in the averaged aerosol concentration, between the control run and the low-aerosol run, there are additional changes in the variability in aerosol distributions. There is a larger frequency of heavy precipitation in the control-homoge run than in the low-aerosolhomoge run (Fig. 7c). However, as mentioned above, there is no strong convergence field which is distinguishable from any other lines in the control-homoge run, as seen in Fig. 13c. Associated with this, differences in the frequency of heavy precipitation between the control-homoge run and the lowaerosol-homoge run are much smaller than those between the control run and the low-aerosol run, particularly during the period between 19:00 and 23:00 LST, as seen in Fig. 7i and 1 . This results in a situation in which differences in the frequency of heavy precipitation between the control-homoge run and the low-aerosol-homoge run are, on average, just $\sim 15 \%$ of those between the control run and the low-aerosol run for the whole simulation period (Fig. 7c). With identical changes in the averaged aerosol concentration between a pair of the control run and the low-aerosol run and a pair of the control-homoge run and the low-aerosol-homoge run, this demonstrates that additional changes in the variability in aerosol distributions play a much more important role in aerosol-induced increases in the occurrence of heavy precipitation than changes in the averaged aerosol concentrations.

\section{Summary and conclusion}

This study examines how aerosol affects heavy precipitation in an urban conurbation area. For this examination, a case that involves an MCS and torrential rain over the conurbation area which is centered in Seoul, South Korea, is simulated. This case has large spatial variability in aerosol concentrations, which involves high-value aerosol concentrations in the western part of the domain and low-value aerosol concentrations in the eastern part of the domain.

It is well-known that increases in aerosol concentrations reduce autoconversion and increase cloud liquid as a source of evaporation, which enhances evaporation and associated cooling. Hence, high-value aerosol concentrations in the western part of the domain cause high-value evaporative cooling rates, while low-value aerosol concentrations in the eastern part of the domain cause low-value evaporative cooling rates. Greater evaporative cooling produces greater negative buoyancy and more intense downdrafts in the western 
part than in the eastern part. More intense downdrafts then turn into stronger outflow over the western part that collides with surrounding air over the eastern part to form a strong convergence field along the boundary between those parts. Over this strong convergence field, most heavy precipitation forms. When contrast in aerosol concentrations between the western and eastern parts, which represents the spatial variability in aerosol concentrations, is reduced together with aerosol concentrations over the western part, differences in evaporative cooling and outflow between those parts decrease substantially. This results in a much weaker convergence field along the boundary, which is followed by much fewer occurrences of heavy precipitation events compared to those with greater contrast. It is found that the changing variability has many more impacts on heavy precipitation than the changing aerosol loading.

Studies (e.g., Niyogi et al., 2006; Thielen et al., 2000) have shown that at the edge of a metropolitan area, due to stark contrast in the surface roughness (representing the surface property) between the area and surrounding rural areas, there are enhanced convergence and updrafts. The urban heat island (UHI) effect, which is associated with the surface property in metropolitan areas, also results in enhanced convergence and updrafts at the edge of the area (Ryu et al., 2013; Schmid and Niyogi, 2017). In addition, a metropolitan area has stronger and more aerosol sources than surrounding rural areas; hence, contrast in aerosol concentrations at the edge of a metropolitan area or at the urban-rural boundary, which is characterized by contrast in the surface property between the urban and rural areas, is unlikely to be rare. This study suggests that in case there is this type of contrast in aerosol properties such as aerosol concentration at the boundary, there can be enhanced convergence and updrafts at the edge of a metropolitan area. Hence, this study suggests that urbanrural contrast in aerosol should be considered as an additional factor (in addition to contrast in the surface roughness and the UHI effect) to understand the enhancement of convergence and updrafts at the edge of a metropolitan area.

It should be noted that urban surface properties, which are represented by the roughness and control the UHI effect, and their contrast with the rural surface properties do not vary significantly with respect to time and space compared to the variation in aerosol properties. Hence, the location of the urban-rural boundary does not change significantly with time and space. However, in contrast to this, aerosol properties vary substantially with respect to time and space and thus the location of boundary between high aerosol concentrations and low aerosol concentrations substantially vary with respect to time and space. For example, in a place such as a large-scale industrial complex within an urban area away from an urban boundary, there can be an increase in aerosol concentrations and thus high aerosol concentrations. These high aerosol concentrations can advect, as exemplified in the case adopted in this study, and a boundary between a place with low aerosol concentrations and a place with high aerosol concentrations can vary spatiotemporally within the urban area. This indicates that the boundary between the place with high aerosol concentrations and that with low aerosol concentrations does not necessarily have to be co-located with the urban-rural boundary, which is characterized by contrast in the surface property between urban and rural areas and whose location does not change much with respect to time and space. Demonstrating this, in this study, the high aerosol-low aerosol boundary, which is, for example, outlined by the purple line in Fig. 4a and b, is not co-located with the urban-rural boundary but located in the middle of the Seoul area. Considering that at the high aerosol-low aerosol boundary, heavy precipitation is concentrated in this study, a spatiotemporal variation in the boundary leads to a spatiotemporal variation in heavy precipitation within an urban area as shown in this study. Hence, while previous theories on urban heavy precipitation can explain heavy precipitation at urban-rural boundaries (characterized by the surface property contrast) and are not able to explain heavy precipitation in various locations within an urban area, the findings in this study elucidate a mechanism behind heavy precipitation in various locations in an urban area and thus give a more comprehensive understanding of torrential rain in urban areas.

There are numerous factors that control the spatial distribution of updrafts and associated condensation. Note that changes in this distribution induce those in the spatial distribution of precipitation that may involve the generation and the enhancement of torrential rain. One of the factors is found to be increasing aerosol concentrations by previous studies (e.g., Khain et al., 2005; Seifert and Beheng, 2006; van den Heever and Contton, 2007; Tao et al., 2007, 2012; Storer et al., 2010; Lee and Feingold, 2013; Lee et al., 2017). These previous studies have found that increasing aerosol concentrations can alter the vertical and horizontal gradient of latent heating and cooling by altering the spatial distributions of freezing, evaporation, and condensation. This alteration leads to that in updrafts, cloud cells, and precipitation, which involves the generation and the enhancement of torrential rain. However, these studies have focused only on increasing aerosol concentrations and assumed that background aerosol concentrations are spatially distributed in a homogeneous fashion and, hence, have not considered the effect of the spatial variability in aerosol on the spatial distribution of latent heat processes, cloud dynamics, and precipitation. For example, previous studies have found that aerosol-induced localized changes in evaporation for individual cloud cells can create subsequent localized changes in the horizontal gradient of latent cooling and temperature in and around individual cloud cells. Note that each of these individual localized changes is limited to each individual localized area in and around each individual cloud cell. These changes lead to the generation and the enhancement of torrential rain in and around individual cloud cells. It is found that increasing spatial variability in aerosol concentrations also increases the gradient of evaporation and temperature. These changes lead 
to increases in the occurrence of heavy precipitation in a specific area which is along the high aerosol-low aerosol boundary and is not limited to a localized area in and around a cloud cell. It is demonstrated that increasing variability plays a much more important role in aerosol-induced increases in the occurrence of heavy precipitation than increases in aerosol concentrations with their homogeneous spatial distributions.

As mentioned, observed aerosol particles include components which do not absorb radiation significantly; hence, the aerosol absorption of radiation is not considered in this study. However, ammonium sulfate and organic compounds, which are observed to comprise aerosol here, reflect and scatter radiation, although this reflection and scattering is not considered in this study. The reflection and scattering of solar radiation by aerosol decreases solar radiation that reaches the surface and thus surface fluxes. Higher aerosol concentrations in the western part of the domain can cause more reflection and scattering of solar radiation by aerosol than in the eastern part. This can reduce surface fluxes, the associated convection intensity, condensation, and transportation of cloud liquid to unsaturated areas by convective motion in the western part more than in the eastern part. As a result, there can be reduction in the contrast in evaporative cooling between the parts compared to the contrast with no consideration of the reflection and scattering. This can lower the intensity and frequency of heavy precipitation by diminishing the contrast in wind field between the parts. However, the simulated intensity and frequency of heavy precipitation with no consideration of the reflection and scattering by aerosol are not that different from observed counterparts. This indicates that the effect of the reflection and scattering by aerosol, and associated changes in surface fluxes on heavy precipitation, is likely to be insignificant in reality. This is likely to be due to the fact that once deep clouds with a high-value cloud fraction and cloud optical depth form, the effect of aerosol on radiation is taken over by that of clouds on radiation, which leads to a situation in which aerosol effects on radiation become negligible compared to cloud effects on radiation.

Data availability. The data used are currently private and stored in our private computer system. Opening the data to the public requires approval from funding sources. Since funding projects associated with this work are still going on, these sources do not allow the data to be open to the public; 2-3 years after these project ends, the data can be open to the public. However, if there is any inquiry about the data, contact the corresponding author Seoung Soo Lee (slee1247@umd.edu).

Author contributions. SSL, BGK, and ZL established essential initiative ideas to start this work. While SSL worked on the analysis of simulation data, BGK and ZL worked on the analysis of observation data. YSC, CHJ, JU, JM, and KHS provided observation data from Korea and participated in their preliminary analysis.
Competing interests. The authors declare that they have no conflict of interest.

Acknowledgements. This research is supported by the Korea Environmental Industry and Technology Institute funded by the South Korean Ministry of Environment as "Climate Change Correspondence Program", the US National Oceanic and Atmospheric Administration (grant NOAA-NWS-NWSPO-2015-2004117), and the National Strategic Project-Fine particle of the National Research Foundation of Korea (NRF) funded by the Ministry of Science and ICT (MSIT), the Ministry of Environment (ME), and the Ministry of Health and Welfare (MOHW) (NRF-2017M3D8A1092022). This research is also supported by Basic Science Research Program through the National Research Foundation of Korea (NRF) funded by the Ministry of Education (2018R1A6A1A08025520).

Edited by: Johannes Quaas

Reviewed by: Annette Miltenberger and one anonymous referee

\section{References}

Bouvette, T., Lambert, J. L., and Bedient, P. B.: Revised rainfall frequency analysis for Houston, J. Hydraul. Div. Proc. Amer. Soc. Civil. Eng., 108, 515-528, 1982.

Brown, A., Milton, S., Cullen, M., Golding, B., Mitchell, J., and Shelly, A.: Unified modeling and prediction of weather and climate: A 25-year journey, B. Am. Meteorol. Soc., 93, 1865-1877, 2012.

Burian, S. J. and Shepherd, J. M.: Effects of urbanization on the diurnal rainfall pattern in Houston: Hydrological processes, Rainfall Hydrol. Proc., 19, 1089-1103, 2005.

Byers, H. R. and Braham, R. R.: The thunderstorm, US Weather Bur., Washington, DC, 287 pp., 1949.

Chen, F. and Dudhia, J.: Coupling an advanced land-surface hydrology model with the Penn State-NCAR MM5 modeling system. Part I: Model description and implementation, Mon. Weather Rev., 129, 569-585, 2001.

Chen, S., Li, W.-B., Du, Y.-D., Mao, C.-Y., and Zhang, L.: Urbanization effect on precipitation over the Pearl River Delta based on CMORPH data, Adv. Clim. Chang. Res., 6, 16-22, 2015.

Dhar, O. N. and Nandergi, S.: The zones of severe rainstorm activity over India, Int. J. Climatol., 13, 301-311, 1993.

Diem, J. E. and Brown, D. P.: Anthropogenic impacts on summer precipitation in central Arizona, USA Prof. Geogr., 55, 343-355, 2003.

Fan, J., Yuan, T., Comstock, J. M., Ghan, S., Khain, A., Leung, L. R., Li, Z., Martins, V. J., and Ovchinnikov, M.: Dominant role by vertical wind shear in regulating aerosol effects on deep convective clouds, J. Geophys. Res., 114, D22206, https://doi.org/10.1029/2009JD012352, 2009.

Fan, J., Rosenfeld, D., Zhang, Y., Giangrande, S. E., Li, Z., Machado, L. A., Martin, S. T., Yang, Y., Wang, J., Artaxo, P., Barbosa, H. M. J., Braga, R. C., Comstock, J. M., Feng, Z., Gao, W., Gomes, H. B., Mei, F., Pöhlker, C., Pöhlker, M. L., Pöschl, U., and Souza, R. A. F.: Substantial convection and precipitation enhancements by ultrafine aerosol particles, Science, 359, 411418, https://doi.org/10.1126/science.aan8461, 2018. 
Fouquart, Y. and Bonnel, B.: Computation of solar heating of the Earth's atmosphere: a new parameterization, Beitr. Phys. Atmos., 53, 35-62, 1980.

Fujibe, F.: Long-term surface wind changes in the Tokyo metropoli$\tan$ area in the afternoon of sunny days in the warm season, J. Meteorol. Soc. Jpn., 81, 141-149, 2003.

Gilliland, E. K. and Rowe, C. M.: A comparison of cumulus parameterization schemes in the WRF model, Proceedings of the 87 th AMS annual meeting: available at: https://ams.confex.com/ams/ pdfpapers/120591.pdf (last access: 24 August 2018), 2007.

Grenci, L. M. and Nese, J. M.: A world of weather: fundamentals of meteorology: a text/ laboratory manual, Kendall/Hunt Publishing Company, 2001.

Holben, B. N., Tanré, D., Smirnov, A., Eck, T. F., Slutsker, I., Abuhassan, N., Newcomb, W. W., Schafer, J. S., Chatenet, B., Lavenu, F., Kaufman, Y. J., Castle, J. V., Setzer, A., Markham, B., Clark, D., Frouin, R., Halthore, R., Karneli, A., O’Neill, N. T., Pietras, C., Pinker, R. T., Voss, K., and Zibordi, G: An emerging ground-based aerosol climatology: Aerosol optical depth from AERONET, J. Geophys. Res., 106, 12067-12097, 2001.

Hwang, S.-O. and Lee, D.-K.: A study on the relationship between heavy rainfalls and associated low-level jets in the Korean peninsula, J. Korean. Meteorol. Soc., 29, 133-146, 1993.

Kain, J. S. and Fritsch, J. M.: A one dimensional entraining/detraining plume model and its application in convective parameterization, J. Atmos. Sci., 47, 2784-2802, 1990.

Kain, J. S. and Fritsch, J. M.: Convective parameterization for mesoscale models: The Kain-Fritsch scheme, The representation of cumulus convection in numerical models, Am. Meteorol. Soc., 24, 165-170, 1993.

Khain, A., Rosenfeld, D., and Pokrovsky, A.: Aerosol impact on the dynamics and microphysics of deep convective clouds, Q. J. Roy. Meteor. Soc., 131, 2639-266, 2005.

Khain, A., BenMoshe, N., and Pokrovsky, A.: Factors determining the impact of aerosols on surface precipitation from clouds: Attempt of classification, J. Atmos. Sci., 65, 1721-1748, 2008.

Khain, A., Pokrovsky, A., Rosenfeld, D., Blahak, U., and Ryzhkoy, A.: The role of $\mathrm{CCN}$ in precipitation and hail in a mid-latitude storm as seen in simulations using a spectral (bin) microphysics model in a 2D dynamic frame, Atmos. Res., 99, 129-146, 2011.

Korea Meteorological Administration: Heavy rainfall events top 10, KMA registered Pub., No. 11-136000-000833-01, Seoul, Korea, 48 pp., 2011.

Lebo, Z.: A numerical investigation of the potential effects of aerosol-induced warming and updraft width and slope on updraft intensity in deep convective clouds, J. Atmos. Sci., 75, 535-554, https://doi.org/10.1175/JAS-D-16-0368.1, 2017.

Lebo, Z. J. and Morrison, H.: Dynamical effects of aerosol perturbations on simulated idealized squall lines, Mon. Weather Rev., 142, 991-1009, 2014.

Lebo, Z. J. and Seinfeld, J. H.: Theoretical basis for convective invigoration due to increased aerosol concentration, Atmos. Chem. Phys., 11, 5407-5429, https://doi.org/10.5194/acp11-5407-2011, 2011.

Lee, D.-K., Kim, H.-R., and Hong, S.-Y.: Heavy rainfall over Korea during 1980-1990. Korean, J. Atmos. Sci., 1, 32-50, 1998.

Lee, S.-S. and Feingold, G.: Aerosol effects on the cloud-field properties of tropical convective clouds, Atmos. Chem. Phys., 13, 6713-6726, https://doi.org/10.5194/acp-13-6713-2013, 2013.
Lee, S. S., Donner, L. J., Phillips, V. T. J., and Ming, Y.: Examination of aerosol effects on precipitation in deep convective clouds during the 1997 ARM summer experiment, Q. J. Roy. Meteorol. Soc., 134, 1201-1220, 2008a.

Lee, S. S., Donner, L. J., Phillips, V. T. J., and Ming, Y.: The dependence of aerosol effects on clouds and precipitation on cloudsystem organization, shear and stability, J. Geophys. Res., 113, D16202, https://doi.org/10.1029/2007JD009224, 2008b.

Lee, S. S., Li, Z., Mok, J., Ahn, M.-H., Kim, B.-G., Choi, Y.-S., Jung, C.-H., and Yoo, H. L: Interactions between aerosol absorption, thermodynamics, dynamics, and microphysics and their impacts on clouds and precipitation in a multiple-cloud system, Clim. Dynam., 49, 3905-3921, https://doi.org/10.1007/s00382017-3552-x, 2017.

Lee, S. S., Penner, J. E., and Saleeby, S. M.: Aerosol effects on liquid-water path of thin stratocumulus clouds, J. Geophys. Res., 114, D07204, https://doi.org/10.1029/2008JD010513, 2009.

Lee, S. S., Kim, B.-G., and Yum, S. S., et al.: Effect of aerosol on evaporation, freezing and precipitation in a multiple cloud system, Clim. Dynam., 48, 1069-1087, 2016.

Li, Z., Niu, F., Fan, J., Liu, Y., Rosenfeld, D., and Ding, Y.: Longterm impacts of aerosols on the vertical development of clouds and precipitation, Nat. Geosci., 4, 888-894, 2011.

Mannan, Md. A., Chowdhury, M. A., and Karmakar, S.: Application of NWP model in prediction of heavy rainfall in Bangladesh, Pac. Sci., 56, 667-675, 2013.

Mladek, R., Barckicke, J., Binder, P., Bougeault, P., Brzovic, N., Frei, C., Geleyn, J. F., Hoffman, J., Ott, W., Paccagnella, T., Patruno, P., Pottier, P., and Rossa, A: Intercomparison and evaluation of precipitation forecasts for MAP seasons 1995 and 1996, Meteorol. Atmos. Phys., 72, 111-129, 2000.

Mlawer, E. J., Taubman, S. J., Brown, P. D., Iacono, M. J., and Clough, S. A.: RRTM, a validated correlated-k model for the longwave, J. Geophys. Res., 102, 16663-1668, 1997.

Morrison, H. and Grabowski, W. W.: Cloud-system resolving model simulations of aerosol indirect effects on tropical deep convection and its thermodynamic environment, Atmos. Chem. Phys., 11, 10503-10523, https://doi.org/10.5194/acp-11-105032011, 2011.

Niyogi, D., Holt, T., Zhong, S., Pyle, P. C., and Basara, J.: Urban and land surface effects on the 30 July 2003 mesoscale convective system event observed in the southern Great Plains, J. Geophys. Res., 111, 1-20, 2006.

Rosenfeld, D., Lohmann, U., Raga, G. B., O’Dowd, C. D., Kulmala, , M., Fuzzi, S., Reissell, A., and Andreae, M. O.: Flood or drought, How do aerosols affect precipitation?, Science, 321, 1309-1313, 2008.

Ryu, Y.-H., Baik, J.-J., and Han, J.-Y.: Daytime urban breeze circulation and its interaction with convective cells, Q. J. Roy. Meteorol. Soc., 139, 401-413, 2013.

Sauer, V. B., Thomas, W. O., Stricker, V. A., and Wilson, K. V.: Flood characteristics of urban watersheds in the United States, United States Geological Survey Water-Supply Paper 2207, 63 pp., 1984.

Schmid, P. E. and Niyogi, D.: Modeling urban precipitation modification by spatially heterogeneous aerosols, J. Appl. Meteorol. Clim., 56, 2141-2153, https://doi.org/10.1175/JAMC-D-160320.1, 2017. 
Seifert, A. and Beheng, K. D.: A two-moment cloud microphysics parameterization for mixed-phase clouds. Part 2: Maritime vs. continental deep convective storms, Meteorol. Atmos. Phys., 92, 67-82, 2006.

Seo, K.-H., Son, J. H., Lee, J.-H., and Park, H.-S.: Northern East Asian monsoon precipitation revealed by air mass variability and its prediction, J. Clim., 28, 6221-6233, 2013.

Shepherd, J. M.: A review of current investigations of urbaninduced rainfall and recommendations for the future, Earth Interact., 9, 1-27, 2005.

Storer, R. L., van den Heever, S. C., and Stephens, G. L.: Modeling aerosol impacts on convection under differing storm environments, J. Atmos. Sci., 67, 3904-3915, 2010.

Takahashi, H.: Secular variation in the occurrence property of summertime daily rainfall amount in and around the Tokyo metropolitan area, Tenki, 50, 31-41, 2003 (in Japanese with an English abstract).

Tao, W.-K., Li, X., Khain, A., Matsui, T., Lang, S., and Simpson, J.: Role of atmospheric aerosol concentration on deep convective precipitation: Cloud-resolving model simulations, J. Geophys. Res., 112, D24S18, https://doi.org/10.1029/2007JD008728, 2007.

Tao, W.-K., Chen, J.-P., Li, Z., Wang, C., and Zhang, C.: Impact of aerosols on convective clouds and precipitation, Rev. Geophys., 50, RG2001, https://doi.org/10.1029/2011RG000369, 2012.

Thielen, J., Wobrock, W., Gadian, A., Mestayer, P., and Creutin, J.-D.: The possible influence of urban surfaces on rainfall development: a sensitivity study in $2 \mathrm{D}$ in the meso- $\gamma$-scale, Atmos. Res., 54, 15-39, 2000.
United Nations, Department of Economic and Social Affairs, Population Division: World urbanization prospects: The $2014 \mathrm{Re}-$ vision, (ST/ESA/SER.A/366), https://esa.un.org/unpd/wup (last access: 24 August 2018), 2015.

van den Heever, S. C. and Cotton, W. R.: Urban aerosol impacts on downwind convective storms, J. Appl. Meteorol. Clim., 46, 828-850, 2007.

van den Heever, S. C., Carrió, G. G., Cotton, W. R., DeMott, P. J., and Prenni, A. J.: Impacts of nucleating aerosol on florida storms. part I: Mesoscale simulations, J. Atmos. Sci., 63, 1752-1775, 2006.

van den Heever, S. C., Stephens, G. L., and Wood, N. B.: Aerosol indirect effects on tropical convection characteristics under conditions of radiative-convective equilibrium, J. Atmos. Sci., 68, 699-718, 2011.

Wang, H., Skamarock, W. C., and Feingold, G.: Evaluation of scalar advection schemes in the Advanced Research WRF model using large-eddy simulations of aerosol-cloud interactions, Mon. Weather Rev., 137, 2547-2558, 2009.

Wang, Y., Zhang, R., and Saravanan, R.: Asian pollution climatically modulates mid-latitude cyclones following hierarchical modelling and observational analysis, Nat. Commun., 5, 3098, https://doi.org/10.1038/ncomms4098, 2014.

Yeh, H.-C. and Chen, G. T.-J.: Case study of an unusually heavy rain event over eastern Taiwan during the Mei-Yu Season, Mon Weather Rev., 132, 320-337, 2004. 